Article

\title{
A Novel Control Strategy on Stable Operation of Fuel Gas Supply System and Re-Liquefaction System for LNG Carriers
}

\author{
Soon-Kyu Hwang ${ }^{1}\left(\mathbb{D}\right.$ and Byung-Gun Jung ${ }^{2, *}$ \\ 1 Process Engineering Department, MODEC Offshore Production System, 9 North Buona Vista Drive, \\ Singapore 138588, Singapore; busan959@gmail.com \\ 2 Department of Marine System Engineering, Korea Maritime \& Ocean University, Busan 49112, Korea \\ * Correspondence: bgjung@kmou.ac.kr; Tel.: +82-51-410-4269
}

Citation: Hwang, S.-K.; Jung, B.-G. A Novel Control Strategy on Stable Operation of Fuel Gas Supply System and Re-Liquefaction System for LNG Carriers. Energies 2021, 14, 8413. https://doi.org/10.3390/en14248413

Academic Editor: Nguyen Van Duc Long

Received: 26 October 2021

Accepted: 18 November 2021

Published: 13 December 2021

Publisher's Note: MDPI stays neutral with regard to jurisdictional claims in published maps and institutional affiliations.

Copyright: (c) 2021 by the authors. Licensee MDPI, Basel, Switzerland. This article is an open access article distributed under the terms and conditions of the Creative Commons Attribution (CC BY) license (https:// creativecommons.org/licenses/by/ $4.0 /)$.

\begin{abstract}
Liquefied natural gas has attracted attention through an explosive increase in demands and environmental requirements. During this period, the Energy Efficiency Design Index (EEDI), which was adopted by the International Maritime Organization, expecting to significantly reduce $\mathrm{CO}_{2}$ from ships, has become an important key. It has triggered a change in use from steam turbine systems and dual fuel diesel electrics to high-efficiency main engines such as ME-GI engines to meet the EEDI requirements. However, since the ME-GI engines use 300 bar of fuel gas pressure, it is necessary to resolve problems of the pressure controllability and to prevent the reductions of the re-liquefaction amount caused by clogging of the lubricant mixed with the fuel gas during the compression. The purpose of this study is to propose a novel control strategy with a newly developed configuration for controlling the pressure so as not to trip the BOG compressors when the ME-GI engines are tripped, and for preventing a reduction on re-liquefaction amount. Unlike the typical configuration used in the current vessels, this proposal separately provides the fuel gas at 150 bar without lubricants to the re-liquefaction. In addition, three control strategies are proposed, depending upon the application of multi-controllers and the location of the pressure transmitters. A simulation was conducted to verify the efficacy of the proposed method, focusing on the controllability of the pressure and the re-liquefaction amount, in comparison with the typical configuration. As results of the simulation, the proposal showed excellent controllability without trips of the BOG compressors even in abnormal conditions and confirmed the great re-liquefaction performance.
\end{abstract}

Keywords: fuel gas supply system; re-liquefaction system; LNG; boil-off gas; pressure control; control strategy; ME-GI engine

\section{Introduction}

Liquefied natural gas (LNG) has attracted attention owing to the explosive demand for increasingly clean energy, environmental regulation of pollutants such as sulfur oxides $\left(\mathrm{SO}_{\mathrm{x}}\right)$ and nitrogen oxides $\left(\mathrm{NO}_{\mathrm{x}}\right)$, and demands for the increased energy efficiency of ships by the International Maritime Organization (IMO) [1-3]. Seeking to minimize airborne emissions in relation to $\mathrm{SO}_{\mathrm{x}}$ and $\mathrm{NO}_{\mathrm{x}}$ from the ships, the IMO added Annex VI to the International Convention for the Prevention of Pollution from Ships (MARPOL) entered into force on 19 May 2005 [4]. In addition, the Energy Efficiency Design Index (EEDI), expected to significantly reduce $\mathrm{CO}_{2}$ from ships, was adopted by the IMO [5]. The EEDI is an important factor for new ship building because it provides a specification for ship design expressed in grams of carbon dioxide $\left(\mathrm{CO}_{2}\right)$ per ship's capacity mile [6]. Attah et al. [7] investigated the impacts of the EEDI regulation on the design of the LNG carriers (LNGCs) equipped with steam turbine propulsion systems (STPSs) and dual fuel diesel electrics (DFDEs). In the case of DFDEs, 97\% satisfied phase 2 but only $56 \%$ satisfied phase 3 , which takes effect in 2025 . Only $6 \%$ of STPSs satisfied phase 0 , and $0.6 \%$ in phase 1 . In this situation, even if LNG, which is considered to be clean energy, is used, high-efficiency 
main propulsion engines are still required to meet EEDI requirements because the quantity of $\mathrm{CO}_{2}$ emissions is roughly proportional to the quantity of fuel consumption [8,9]. The ME-GI engines show the highest efficiency and lowest fuel consumption than the Otto-cycle engines [10]. DFDE fuel consumption is about 14\% higher than that of ME-GI engines, so high-efficiency main propulsion engines such as ME-GI engines are essential to meet EEDI requirements. Unlike STPSs, internal combustion engines for main propulsion can be operated only by boil-off gas (BOG) without forced vaporization of the LNG, and it is not necessary to use a gas combustion unit (GCU) to control the pressure of cargo tanks because LNGCs are equipped with a re-liquefaction system.

Despite these advantages, the fuel gas supply systems (FGSSs) for ME-GI engines have difficulty controlling the appropriate pressure at the downstream of the BOG compressors owing to the 300 and above bar of high pressure from equipment trips such as those in ME-GI engines. That is, the FGSS reaches the trip setting pressure of the BOG compressor in a short time. For high-pressure application on the reciprocating compressors, adequate lubrication should be supplied in the cylinder liner to prevent piston ring damage through the gap between the piston and liner [11]. This lubricant may be supplied with the fuel gas compressed to 300 bar to the re-liquefaction system. When the lubricant included in the fuel gas is supplied to a printed circuit heat exchanger (PCHE) that has zig zag lines in semi circles across sections of about $1.8 \mathrm{~mm}$ in diameter, as described in Figure 1, the lubricant oils are frozen by cold heat $[12,13]$. This causes some clogging in the PCHE, which is the reason for lowering the re-liquefaction amount. In addition, it results in maintenance work to remove the clogging of the lubricant oil in the PCHE. During this maintenance, the use of the re-liquefaction system may not be possible. In other words, the GCU may be required to properly regulate the pressure in the cargo tanks.

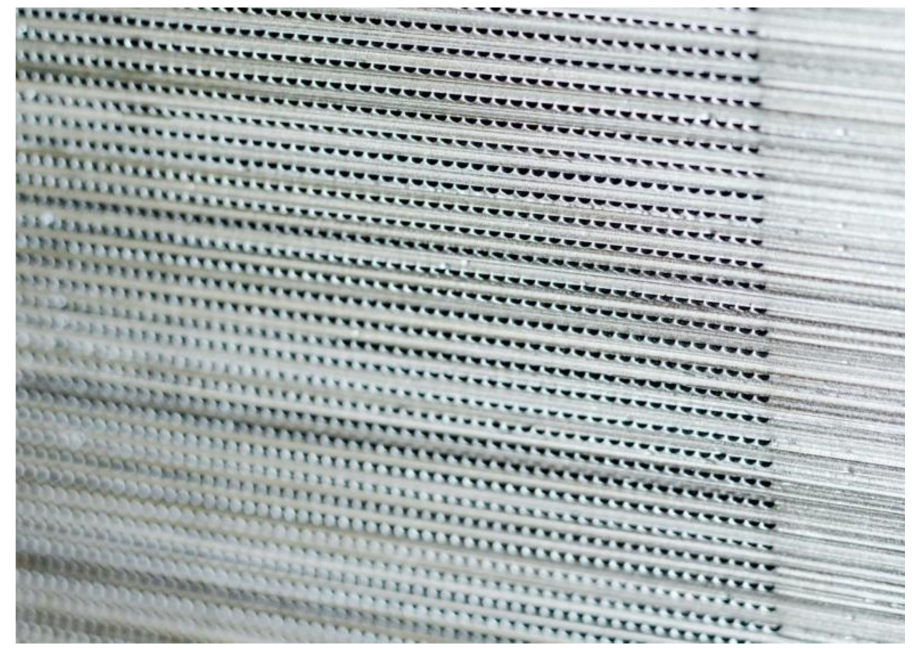

Figure 1. Inside configuration of printed circuit heat exchanger (PCHE) [13].

The primary contribution of this study is the proposal of a new configuration that does not include lubricants in the fuel gas for the re-liquefaction system and that develops a good control strategy for the fuel gas pressure in abnormal conditions such as trips. First, we suggest novel system configurations of the FGSS and re-liquefaction system. Some researchers have investigated the FGSS and re-liquefaction system. Fernández et al. [14] reviewed propulsion systems on LNG carriers. Park et al. [15] suggested FGSSs for LNG fuel focusing on its economic feasibility. Tan et al. [16] developed an efficient re-liquefaction system using a dual-mixed refrigerant cycle. Kim et al. [17] investigated the economic optimization of re-liquefaction systems and FGSSs. However, these studies focused on performance and economic optimization. Some studies have concentrated on the lubrication effects in heat exchangers. A study on the influence of the lubricant oil on the heat transfer performance inside small diameter tubes was carried out by Wei et al. [18]. Ngoctan et al. [19] performed an experiment to describe the effect of lubricant oil on the 
heat transfer performance. The result of this study was that all heat transfer coefficients were significantly deteriorated compared to pure refrigerants when the oil concentration exceeded $5 \%$. These studies have focused on the performance of heat exchangers and the effect of lubricants on heat transfer in the heat exchangers. However, a high-pressure FGSS and a re-liquefaction system are needed that are not affected by lubricating oil and allow stable operation with little maintenance of the heat exchangers and good performance of the FGSS and re-liquefaction system. In the case of a general system equipped with ME-GI engines, 300 bar of BOG is supplied to the re-liquefaction system and the ME-GI engines at the last stage of the multi-stage reciprocating compressors, which usually have 5-6 stages. In this paper, 6-stage compressors with lubricants are used as a new configuration. At the 6th stage of the compressors, the fuel gas at 300 bar is supplied to the ME-GI engines. At the 5th stage of the BOG compressors, the BOG at 150 bar, which does not include lubricant oils, is provided for the re-liquefaction system.

Appropriate control strategy should then be applied to the new configuration of the FGSS and the re-liquefaction system. The purpose of this new control strategy is to efficiently prevent trips of the BOG compressor when the ME-GI engines are tripped. The ME-GI engine trips are considered to be a severe case of abnormal operations because they use the largest amount of BOG, with the exception of the re-liquefaction system. The reason for not considering the re-liquefaction system that handles more BOG is that there is a rare possibility of the trip, excepting for the Joule-Thompson valves. Several studies have concentrated on control strategies for minimizing energies or optimizing the normal operation of the FGSS and the re-liquefaction system. Won et al. [20] suggested minimizing energy with a control system using a model predictive controller for the re-liquefaction equipment. A simulation study was conducted for optimizing normal operation of the charge or preventing leakage of a refrigerant for mixed refrigerant cycle [21]. Abnormal operations have been investigated by some researchers. Kim et al. [22] developed a propane-mixed refrigerant liquefaction process for a small scale LNG plant that considers the normal start-up and steady state of the operation. Yang et al. [23] concentrated on transient cooling performance for the stable operation and control of the refrigerator. However, little attention has been paid to perspectives on abnormal operation such as ME-GI engine trips. In ships, gas trips of the main engines can occur for several reasons. If this makes the BOG compressors trip, the re-liquefaction system will also be tripped and eventually the pressure of the cargo tank will rise. This, in turn, leads to gas consumption in the GCU, producing poor results from the operational expenditure (OPEX) perspective and system stability.

When applied to LNGC's re-liquefaction system and the FGSS, the BOG compressors must be kept in operation even if there are trips in large gas consumers such as ME-GI engines. In addition, there should be no impact of lubricant oils on the re-liquefaction system. Considering these points, a novel configuration and control strategies are suggested in this work for the re-liquefaction system and the FGSS. Using dynamic simulations by UniSim R.460.2 (Honeywell Process Solutions, Houston, TX, USA), the performance of a novel configuration with the suggested control strategies is reviewed and compared to the typical configuration used in the LNGCs.

\section{LNG Processes and Control Strategy}

A total of four cases are explained of FGSSs with re-liquefaction systems in LNGCs. A typical FGSS with a re-liquefaction system is first described, and then three cases are outlined that reflect different control strategies in the new configuration.

\subsection{Case A: Typical Fuel Gas Supply System (FGSS) with Full Re-Liquefaction System (FRS)}

A partial re-liquefaction system (PRS) developed by Lee et al. [24] was adopted in this study. Although this is a typical configuration applied to LNGCs equipped with ME-GI engines, the full re-liquefaction system (FRS) that operates BOG compressors in parallel to liquefy a large amount of BOG during the voyage was applied to this paper. Figure 2 
describes a typical FGSS with the FRS. First, the BOG stream S1 generated from cargo tanks flows into the PCHE to heat exchange the cryogenic temperature at about $-120^{\circ} \mathrm{C}$ with the compressed fuel gas streams S7 and S13 at $45^{\circ} \mathrm{C}$. The compressed fuel gas of streams S5 and S11 is generally supplied to DFGEs by two BOG compressors at approximately the same mass flowrate. Pressure-regulating valves (PRVs) are applied because the pressure of the fuel gas at the S5 and S11 streams is higher than the value required by DFGEs. The fuel gas is compressed to 300 bar to be used in the ME-GI engines and re-liquefaction system through 5-stage compressors. During the time for compression to reach 300 bar, the lubricant oil is injected in the last stage of the compressors to prevent damage to the piston rings.

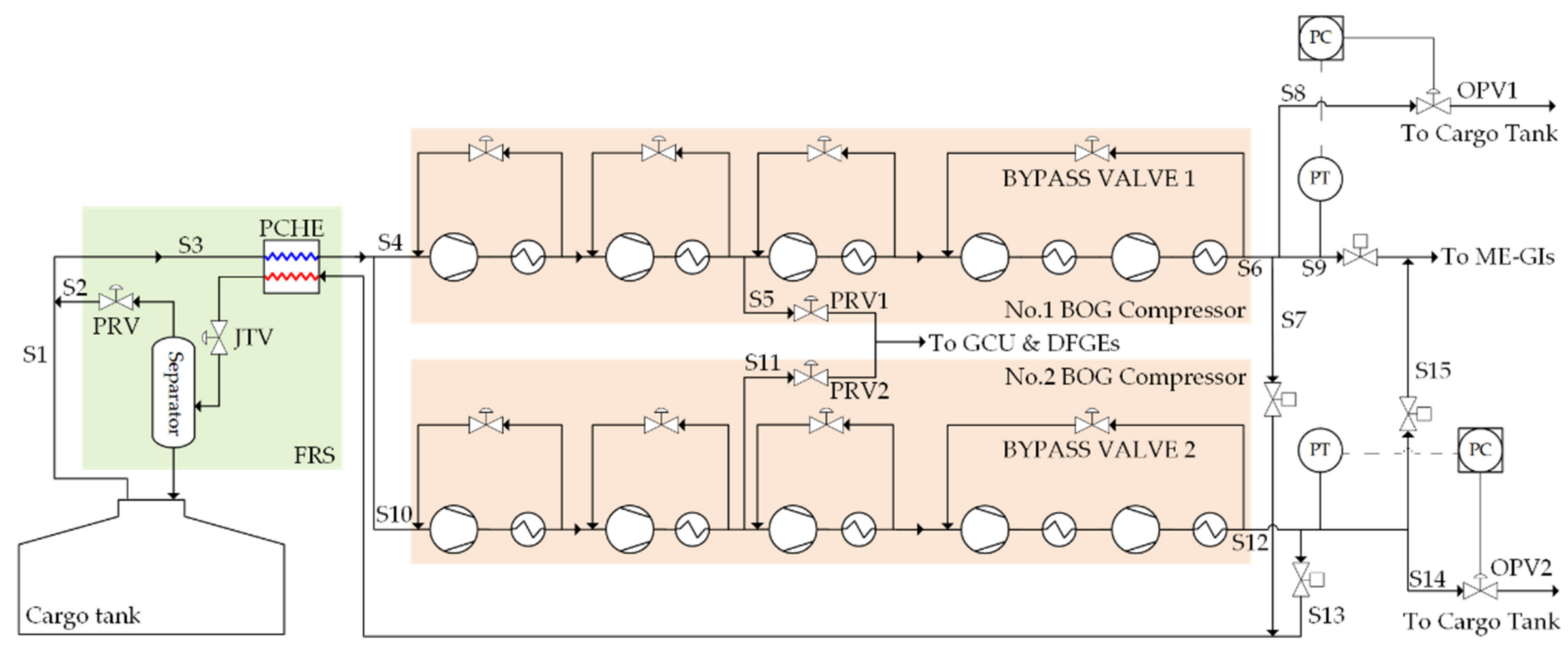

Figure 2. Configuration of a typical fuel gas supply system with a full re-liquefaction system (Case A).

Some fractions (streams S9 and S15) include the lubricant oil in the fuel gas flow to the ME-GI engines. The remaining fuel gas (streams S7 and S13) flows to the re-liquefaction system. The flowrates of each stream for S7 and S13 are controlled by the Joule-Thompson valve (JTV) in order to keep a constant discharge pressure of the BOG compressors in the streams S6 and S12. If the pressure in streams S6 and S12 rises slightly from a sudden reduction in the gas flowrate in the ME-GI engines or from slow action of the JTV, the pressure is first adjusted by the bypass valve as shown in Figure 3. The bypass valve serves to adjust the discharge pressure of the BOG compressors using a multi-controller (UC) acting as a low selector either by the upstream pressure or by the downstream pressure $[25,26]$. The bypass valves 1 and 2 between the upstream and downstream of the 5th compressors are set to 300 bar in Figure 2. If the pressure in streams S6 and S12 is increased to 308 bar, despite the bypass valves being activated, the over-pressure control valves 1 and 2 (OPVs) are opened and adjust the pressure in streams S6 and S12. At this time, the gas that has passed through the OPVs is sent to the cargo tanks at a pressure slightly higher than that of the cargo tanks, considering the pressure loss through the piping routed from the OPVs to the cargo tanks.

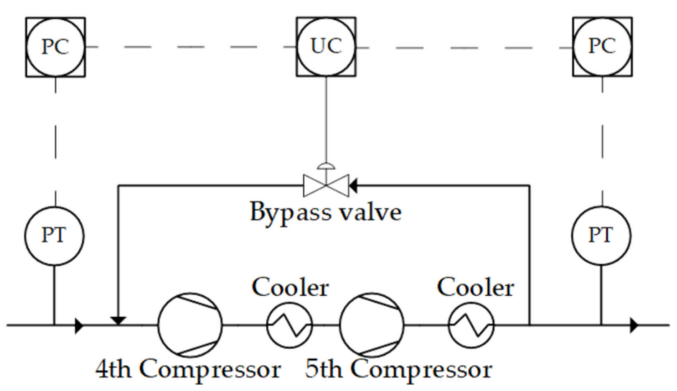

Figure 3. Configuration of a bypass valve in compressor skid [27]. 


\subsection{Case B: Novel Fuel Gas Supply System with Full Re-Liquefaction System and Control Philosophy I}

This case adopts a novel configuration of the FGSS with the re-liquefaction system. Compared to Case A, major changes are the application of the 6-stage BOG compressors, a re-liquefaction pressure change from 300 to 150 bar, and a control philosophy with one more OPV. Figure 4 shows a novel FGSS with the FRS. In order to create pressure of 150 bar (streams S6 and S12) for the re-liquefaction system, 6-stages compressors are needed, unlike Case A, owing to the limitation on the compression ratio. As a result, its configuration is changed from 5-stages to 6-stages, compared to Case A. No lubricant is used up to the 5th stages, and it is only applied in the 6th stage of the BOG compressors. The fuel gases (streams S9 and S15) are supplied to ME-GI engines only from the 6th stage compressors. If the pressure in the streams S9 and S15 is slightly high, it is controlled by bypass valves 1 and 2 located between upstream and downstream of the 6th compressors to create 300 bar. Even if controlled by bypass valves, the OPVs will be operated if the pressure in streams S9 and S15 rises further. In case of exceeding 308 bar in the pressure transmitters installed in streams S9 and S13, the OPV of the 150 bar line near stream S16 is activated through a multi-controller (UC). This is the reason for reducing the flowrate into the 6th stage compressor. In addition, the OPV of the corresponding stream is activated if streams S8 and S14 exceed 308 bar. In most cases, the pressure of stream S16 is increased because of the trip of consumers of a large amount of flowrate, such as ME-GI engines, so an OPV located at stream S16 is controlled through the pressure transmitters of streams of S9 and S15.

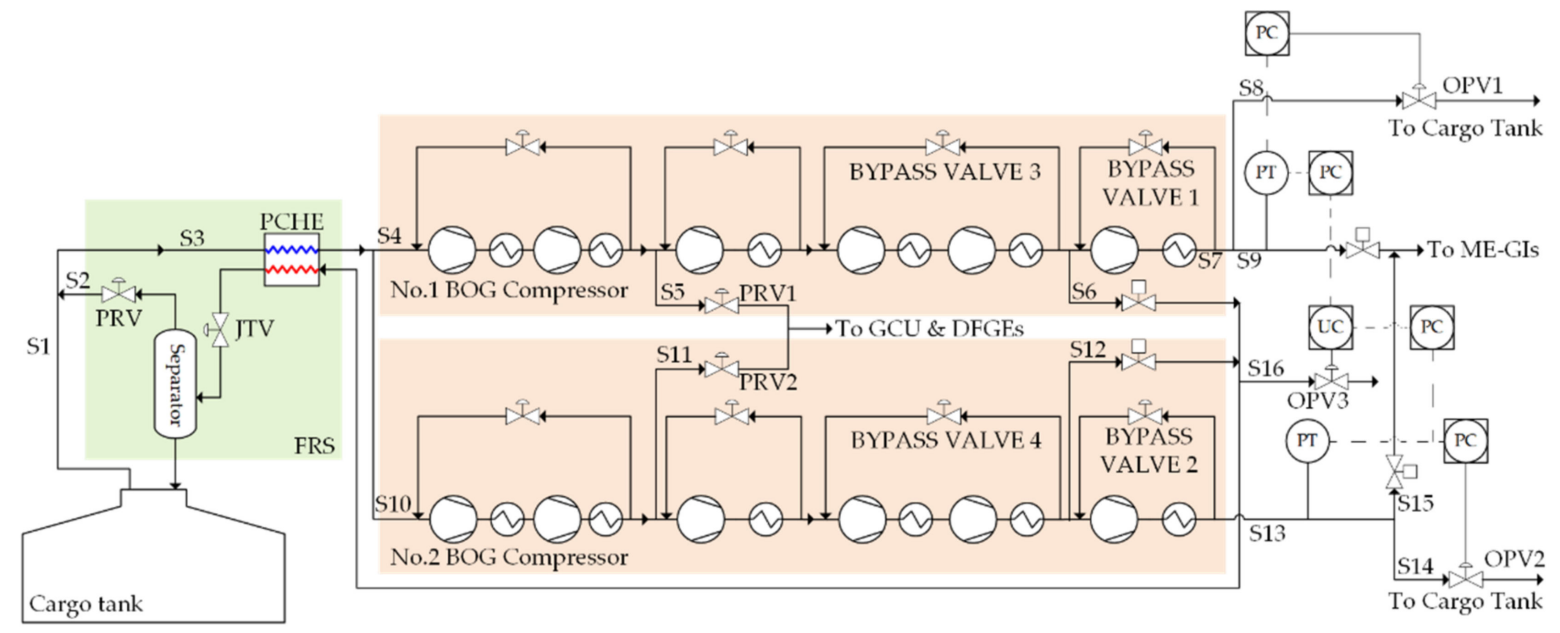

Figure 4. Configuration of a novel fuel gas supply system with a full re-liquefaction system (Case B).

\subsection{Case C: Novel Fuel Gas Supply System with Full Re-Liquefaction System and Control Philosophy II}

There is a main difference between Case B and Case C. Case C has a separate pressure transmitter in a stream S16 compared to Case B. When the pressure is high in the reliquefaction system, the OPV 3 is activated for adjusting on the pressure by a stream S16. However, in Case B, stream S16 located at the 150 bar re-liquefaction system is controlled by the pressure of the pressure transmitters installed at streams S9 and S13. If the pressure is high in stream S9 or S15, or both, the OPVs installed in streams S8 and S14 are activated by the signals from each pressure transmitter near streams S9 and S13. Case C is an approach that faithfully follows the conventional control where the pressure in each line should be controlled according to each pressure set value, as shown in Figure 5. If the pressure rises in the re-liquefaction system's piping lines, it must be controlled by the OPV installed on stream S16, except for streams S9 and S15 of the ME-GI engines. The pressure is controlled by the OPV located at stream S8 if the pressure rises only in stream S9. That is the control system in which the OPV of each piping line is controlled by the PT of each piping line. 


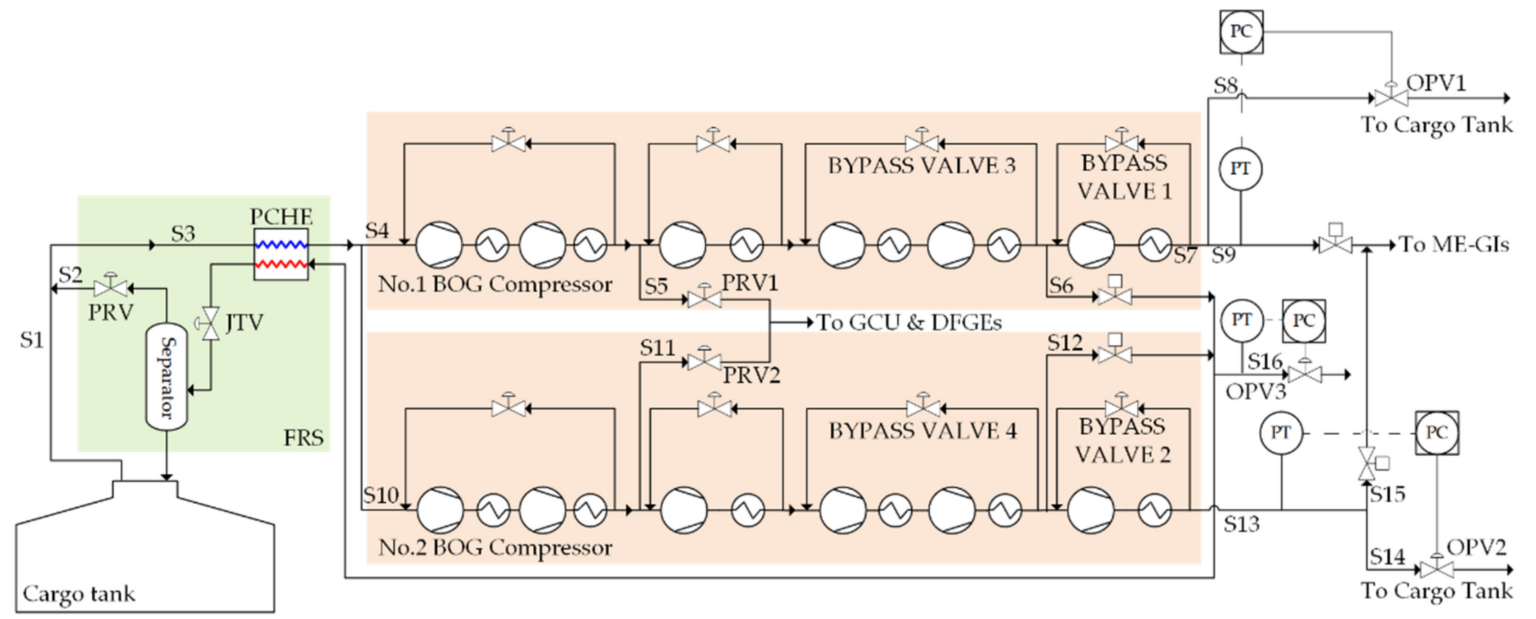

Figure 5. Configuration of a novel fuel gas supply system with a full re-liquefaction system (Case C).

\subsection{Case D: Novel Fuel Gas Supply System with Full Re-Liquefaction System and Control Philosophy III}

This case adopts a more comprehensive control system than Case A, Case B, and Case C, as shown in Figure 6. This control system consists of three PTs, five pressure controllers (PCs), and one multi-controller (UC). This is a combination of the conventional control strategy (Case C), having each pressure transmitter and each pressure controller, and the control strategy (Case B) that considers trips in the ME-GI engines that consume a lot of fuel gas. In order to combine the benefits of a conventional control strategy and a quick response in the event of a trip in the ME-GI engines, a multi-controller receives signals from each controller using each pressure transmitter. The highest value is used in a multi-controller to enable an OPV of the 150 bar piping line (stream S16). During this time, the pressure of streams S9 and S15 are controlled by each pressure controller using the pressure signals installed near streams of S9 and S13.

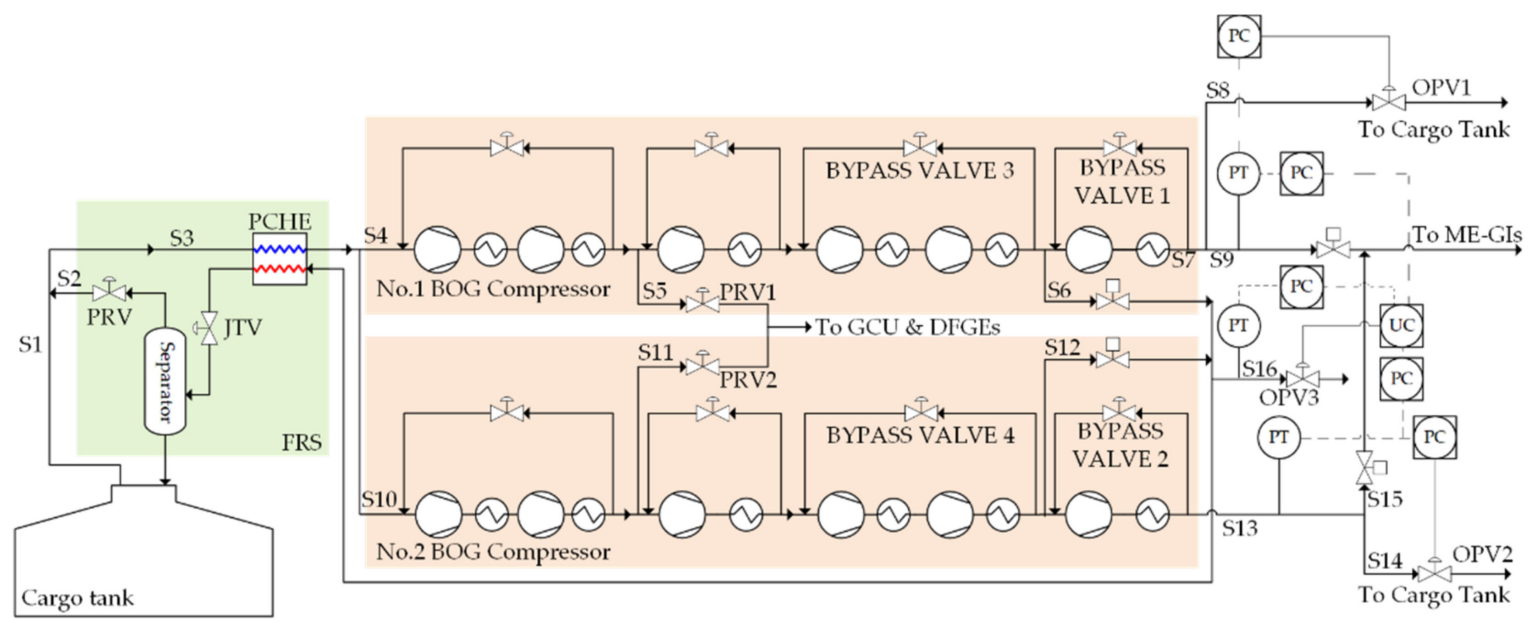

Figure 6. Configuration of a novel fuel gas supply system with a full re-liquefaction system (Case D).

\section{Design Basis}

In this paper, the scope of dynamic simulation models in UniSim R.460.2 is limited to the fuel gas supply system and the re-liquefaction system on LNGCs. The other subsystems such as a gas combustion unit, the ME-GI engines, the DFGEs, and cooling water systems were excluded. Only the quantity of gas consumption for the ME-GI engines and DFGEs was used. In the simulations, the fuel gas supply system and the re-liquefaction system were simulated using the Peng-Robinson equation of state in UniSim R.460.2. 


\subsection{Boil-Off Gas}

The LNG used in this simulation assumed that the total amount of the gross heating values was within acceptable limits in the Europe market [17,28]. In addition, the flowrates required for the ME-GI engines and DFGEs used different lowering heating values, so the lower heating value of the LNG was set at $50 \mathrm{MJ} / \mathrm{kg}$ for convenience in calculating the flowrate required by the ME-GI engines and DFGEs. Table 1 shows compositions of the LNG based on the gross heating values and lower heating values.

Table 1. Chemical composition of LNG.

\begin{tabular}{cc}
\hline Composition (Unit) & Mole Fraction \\
\hline Methane (mol \%) & 0.9589 \\
Ethane (mol \%) & 0.0296 \\
Propane (mol \%) & 0.0072 \\
Butane (mol \%) & 0.0006 \\
Nitrogen (mol \%) & 0.0037 \\
\hline
\end{tabular}

The boil-off ratio (BOR) and mass flowrate of the boil-off gas are calculated using Equations (1) and (2) [29,30].

$$
\begin{gathered}
\text { Boil - Off Ratio }=\frac{Q \times 24 \times 3600}{V \times \rho \times H_{v}} \times 100 \\
\dot{m}=\frac{B O R \times F L \times V \times \rho}{24 \times 100 \times 100}
\end{gathered}
$$

where $Q$ is total heat flows $(\mathrm{w})$ penetrated inside each cargo tank; $V$ is the total volume $\left(\mathrm{m}^{3}\right)$ of the LNG in the cargo tanks; $\rho$ is the density $\left(\mathrm{kg} / \mathrm{m}^{3}\right)$ of the LNG; $H_{v}$ is enthalpy $(\mathrm{kJ} / \mathrm{kg})$ for vaporization of the LNG; $\dot{m}$ is mass flowrate $(\mathrm{kg} / \mathrm{h})$ of the BOG; BOR is boil-off ratio (\%); $F L$ is filling limit of allowable maximum volume in the cargo tanks (\%); $V$ is the total volume of the cargo tanks $\left(\mathrm{m}^{3}\right)$ in the LNG carrier.

The cargo tank size of $170,000 \mathrm{~m}^{3}$ was considered in this paper, and the insulation of the GTT NO96 GW was applied. Filling limits of the cargo tanks were considered as a volume equivalent to $98 \%$ full following the IMO requirements [31]. According to Equation (1) and the GTT information, a daily BOR of $0.125 \%$ was used [32]. Based on the $0.125 \%$ BOR, the LNG compositions, cargo tank size, and the filling limits of the cargo tanks, $3713 \mathrm{~kg} / \mathrm{h}$ of the mass flowrate for BOG was expected. Table 2 shows the composition of the BOG calculated.

Table 2. Chemical compositions of the BOG.

\begin{tabular}{cc}
\hline Composition (Unit) & Mole Fraction \\
\hline Methane $(\mathrm{mol} \%)$ & 0.9994 \\
Ethane $(\mathrm{mol} \%)$ & 0.0004 \\
Nitrogen $(\mathrm{mol} \%)$ & 0.0002 \\
\hline
\end{tabular}

\subsection{Equipment}

\subsubsection{Compressors}

In general, two specifications are required in the dynamic simulation of the reciprocating compressors. The first is polytropic efficiency or adiabatic efficiency. The polytropic efficiency or adiabatic efficiency is a value used to describe the efficiency of a compressor. In the case of positive displacement, the adiabatic efficiency is normally used. The adiabatic 
efficiency was used for the dynamic simulation in the UniSim. The adiabatic efficiency was determined from Equation (3) [33] and was considered to be $75 \%$ in this paper.

$$
\text { Adiabatic efficiency }=\frac{\left(H_{\text {disch }}-H_{\text {suc }}\right)_{(\text {ideal })}}{\left(H_{\text {disch }}-H_{\text {suc }}\right)_{(\text {actual })}}
$$

where $H$ is enthalpy $(\mathrm{kJ} / \mathrm{kg})$.

The second is the rotational speed of the shaft driving the reciprocating compressors. The motor speed can be used for the reciprocating compressors. The motor speed applied in this simulation was $3750 \mathrm{rpm}$.

\subsubsection{Heat Exchangers}

The heat exchanger (PCHE) is used for energy balance by the hot and cold fluids in steady state calculation. Equation (4) applies for some layers in the PCHE when there are no balance errors [33].

$$
M_{\text {cold }}\left(H_{\text {out }}-H_{\text {in }}\right)-Q_{\text {leak }}=M_{\text {hot }}\left(H_{\text {in }}-H_{\text {out }}\right)-Q_{\text {loss }}
$$

where $M$ is fluid flowrate $(\mathrm{kg} / \mathrm{h})$ in the layers of the PCHE; $H$ is enthalpy $(\mathrm{kJ} / \mathrm{kg}) ; Q$ is heat loss or leakage $(\mathrm{kJ})$.

The steady state calculation is based on heat balances, specifications in relation to temperatures, and enthalpy. However, the overall heat transfer coefficient $(U)$ is important because it indicates the amount of heat exchanged in the physical layout of the exchanger in the dynamic simulation. The $U A$ value in Equation (5) is used for the dynamic simulation $[34,35]$.

$$
Q=U A \times \Delta T_{L M}
$$

where $U$ is a heat transfer coefficient $\left(\mathrm{kJ} /{ }^{\circ} \mathrm{C} \cdot \mathrm{m}^{2} \cdot \mathrm{h}\right) ; A$ is heat transfer areas $\left(\mathrm{m}^{2}\right) ; \Delta T_{L M}$ is $\log$ mean temperature difference (LMTD) $\left({ }^{\circ} \mathrm{C}\right)$.

\subsubsection{Valves}

The valves play an important role among the many elements of the process plant, especially the control valves. If the flowrate is not controlled properly, pressure control may be difficult. The dynamic characteristic is explained by the flow coefficient $(\mathrm{Cv})$. In order to determine the flow coefficients of the control valves, definition of the $k$ value is necessary. The $k$ value is defined by Equation (6) [36].

$$
k=\frac{M}{\sqrt{\rho \times \text { opening ratio } \times\left(P_{\text {suc }}-P_{\text {disch }}\right)}}
$$

where $M$ is mass flow rate $(\mathrm{kg} / \mathrm{h}) ; \rho$ is density $\left(\mathrm{kg} / \mathrm{m}^{3}\right)$; opening ratio is the valve's opening ratio (\%); $P_{\text {suc }}$ is inlet pressure of the valve $(\mathrm{kPa}) ; P_{\text {disch }}$ is outlet pressure of the valve $(\mathrm{kPa})$.

\subsection{Controller}

The controller is the primary means to properly manipulate the model in the dynamic simulation. A manipulated variable (MV) of the model is adjusted using the difference between a set value (SV) and a process variable (PV) as shown in Figure 7. 


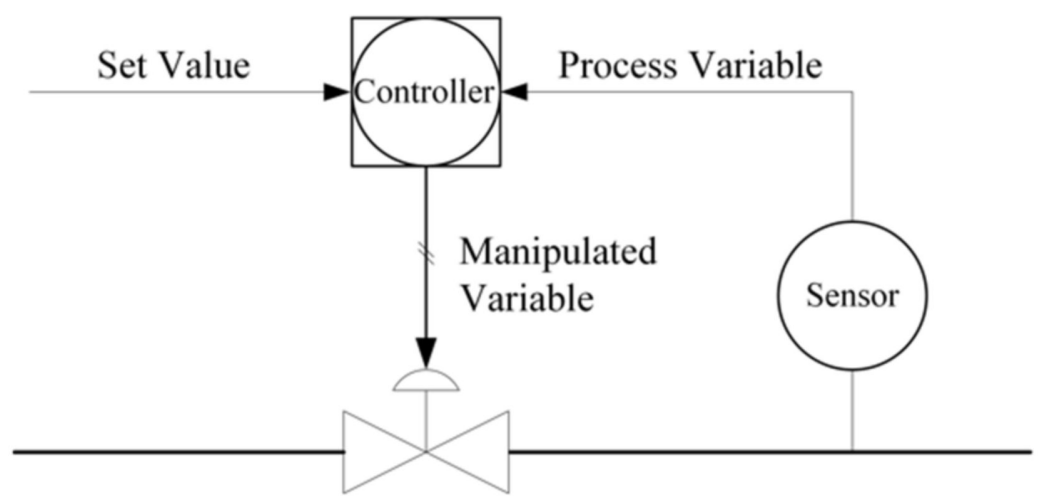

Figure 7. General configuration of a process variable, a manipulated variable, and a set value.

A proportional-integral-derivative (PID) controller is the most common structure for adjusting on manipulated variables in the industries of the process control. This PID controller is constructed by various combinations of the proportional, integral, and derivative in order to guarantee a specific performance. However, the derivative control function was not used because this differential action wildly amplifies the noise when a process measurement for a process variable has a noise such as a high frequency [37]. In addition, even if the SV is fixed, high-pressure systems with more than 150 bar change the PV rapidly in a short time, creating a rather dramatic change by the derivative. This measure eventually leads to impact in controlling the system. The controller output based on the parallel PI controller and an error value are represented in Equations (7) and (8) [38].

$$
\begin{gathered}
\text { Controller output }=k_{P} E(t)+k_{I} \int E(t) d t=k_{P}\left[E(t)+\frac{1}{T_{I}} \int E(t) d t\right] \\
E(t)=P V(t)-S V(t)
\end{gathered}
$$

where $k_{P}$ is a proportional gain of the controller; $k_{I}$ is an integral gain of the controller; $T_{I}$ is an integral time of the controller; $E(t)$ is an error value at time $t ; P V(t)$ is a process variable at time $t ; S V(t)$ is a set value at time $t$.

\subsection{Fuel Gas Consumption}

Two types of engines consume the fuel gas. One is the main propulsion engine called the ME-GI engine. The other is the DFGE for generators. The flowrate of the fuel gas required by the ME-GI engines and DFGEs is defined by Equation (9) $[39,40]$.

$$
\dot{m}=\frac{L H V_{A}}{L H V_{B}} \times m_{s} \times P
$$

where $P$ is required power $(\mathrm{kW})$ for propulsion of the ship or the power generation; $m_{S}$ is specific fuel consumption $(\mathrm{kJ} / \mathrm{kWh}) ; L H V_{A}$ is lower heating value of the actual fuel gas $(\mathrm{kJ} / \mathrm{kg}) ; L H V_{B}$ is the lower heating value of the fuel gas $(\mathrm{kJ} / \mathrm{kg})$ when designing an engine.

In this paper, two sets of 5G70ME-GIs, which have an output of 10,000 kW at nominal continuous rating (NCR), were selected for the main propulsion [17]. Specific gas consumption was $131.2 \mathrm{~g} / \mathrm{kWh}$ at NCR of the ME-GI engine [40]. This specific gas consumption is converted to $4985.6 \mathrm{~kJ} / \mathrm{kWh}$ according to the manufacturer's reference value. For DFGEs, four sets of 6L34DF with an output of $2768 \mathrm{~kW}$ were applied in this simulation and used to calculate the fuel gas consumption. The reason for choosing $6 \mathrm{~L} 34 \mathrm{DF}$ was to consider the amount of power required for the BOG compressor's parallel operation and associated systems related to the operation of the ship. The specific gas consumption for DFGEs was $7526.0 \mathrm{~kJ} / \mathrm{kWh}$ [41]. Table 3 represents each engine's specification applied in this paper. 
Table 3. Engine specifications.

\begin{tabular}{cccc}
\hline System & Engine Type & Power at NCR & Specific Gas Consumption \\
\hline ME-GI engine & 5G70ME-GI & $10,000 \mathrm{~kW}$ & $4985.6 \mathrm{~kJ} / \mathrm{kWh}$ \\
DFGE & 6L34DF & $2768 \mathrm{~kW}$ & $7526.0 \mathrm{~kJ} / \mathrm{kWh}$ \\
\hline
\end{tabular}

\section{Simulation Results}

The main purpose of this simulation is to investigate how efficiently the controllability of the proposed control schemes adjusts the system compared to Case A in Figure 2 during trips of the ME-GI engines. However, the start-up and stop for the FGSS and the re-liquefaction system is not considered in this study, because they are normal operations.

When the highest fuel-gas-consuming ME-GI engines are tripped, the BOG compressors should not be tripped. The BOG compressors have a trip function to protect physical damages from the downstream pressure of the BOG compressors. If the BOG compressors are tripped in succession by the trip of the ME-GI engines, even the re-liquefaction system will be unavailable, raising the pressure inside the cargo tanks for a long time. As the last alternative, BOG will be burned by the GCU using free-flow by cargo tank pressure.

After investigation into the controllability of the proposed control schemes, re-liquefaction capability is examined. Because the pressure for the re-liquefaction system is changed from 300 to 150 bar, it makes an impact on the decrease in the amount of the re-liquefaction. However, if the amount of BOG consumed by the various engines and the quantity of the re-liquefaction are greater than the amount of the BOG generated in the cargo tanks, it is considered to have sufficient performance for the BOG pressure management by the FGSS and the re-liquefaction system.

\subsection{Controllability Analysis}

Controllability analysis is examined by the effectiveness of controlling the downstream pressure of the BOG compressors when one of the ME-GI engines or the two ME-GI engines is tripped. During this time, the bypass valves installed between the upstream and the downstream of the BOG compressors and the OPVs are used for controlling the downstream pressure of the BOG compressors as shown in Figure 8.

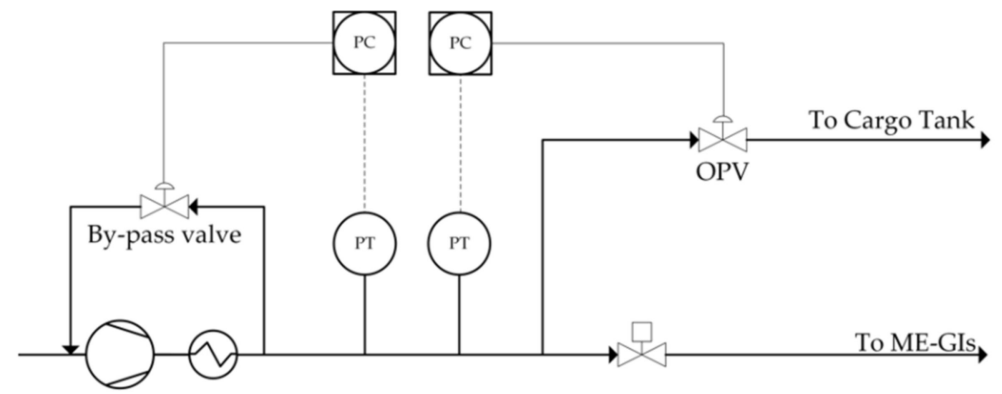

Figure 8. Control configuration for controlling downstream pressure of a BOG compressor.

If the downstream pressure of the BOG compressors exceeds 300 bar, bypass valves start to open to maintain 300 bar at the downstream of the BOG compressors. However, if the pressure rises further to 308 bar, the downstream pressure is controlled by the OPVs and the bypass valves. The BOG compressors are tripped when the pressure rises to 323 bar in the downstream of the BOG compressors despite both valves being actuated. During the pressure change, the JTV is also controlled according to the upstream pressure of the re-liquefaction system. For the newly proposed Cases B, C, and D, 150 bar is maintained by the bypass valves installed at the BOG compressors, and the OPVs are used to regulate the pressure in the case exceeding 154 bar at the upstream of the re-liquefaction system. When it reaches 163 bar, the BOG compressors are tripped. Table 4 summarizes the pressure setting values in the upstream of the ME-GI engines and the re-liquefaction system, from 
Case $\mathrm{A}$ to Case $\mathrm{D}$ in this work. The setting value of the trip for the BOG compressors is referred from ME-GI engine's design pressure [40].

Table 4. Pressure setting values.

\begin{tabular}{cccccc}
\hline $\begin{array}{c}\text { System } \\
\text { (unit) }\end{array}$ & Action Item & Case A & Case B & Case C & Case D \\
\hline ME-GI & Bypass & 300 & 300 & 300 & 300 \\
(bar) & OPV & 308 & 308 & 308 & 308 \\
& Trip & 323 & 323 & 323 & 323 \\
\hline \multirow{2}{*}{ Re-liquefaction } & Bypass & 300 & 150 & 150 & 150 \\
(bar) & OPV & 308 & 154 & 154 & 154 \\
& Trip & 323 & 163 & 163 & 163 \\
\hline
\end{tabular}

A simulation where one ME-GI engine or two ME-GI engines are suddenly tripped on an LNGC navigating at a speed of 19 knots is considered, which uses the most fuel gas of the ME-GI engines. The amount of the fuel gas used per ME-GI engine in navigation at 19 knots is calculated by Equation (9), and the calculation result is $1250 \mathrm{~kg} / \mathrm{h}$ at $45^{\circ} \mathrm{C}$ based on the gas compositions of Table 2. For DFGEs, the fuel gas consumption is $900 \mathrm{~kg} / \mathrm{h}$ at the same temperature and gas compositions used in ME-GI engines. The BOG compressors applied in this simulation supply a total of $4900 \mathrm{~kg} / \mathrm{h}$ of the fuel gas to ME-GI engines, DFGEs, and re-liquefaction systems.

\subsubsection{Case A Results}

We first examine the controllability of the system using the trip of the one engine. When the No.1 ME-GI engine is tripped, the downstream pressure of each BOG compressor rises to 316.2 bar, as shown in Figure 9. In case of the FRS, its pressure rises to 315.8 bar. The downstream lines for ME-GI engines are connected to one piping line so it shows the trends of the similar pressures. However, the maximum pressure of the FRS pipeline is different from the maximum pressure of the ME-GI line. The reason is that a JTV deals with a relatively higher flowrate than the OPVs during the No.1 ME-GI trip.

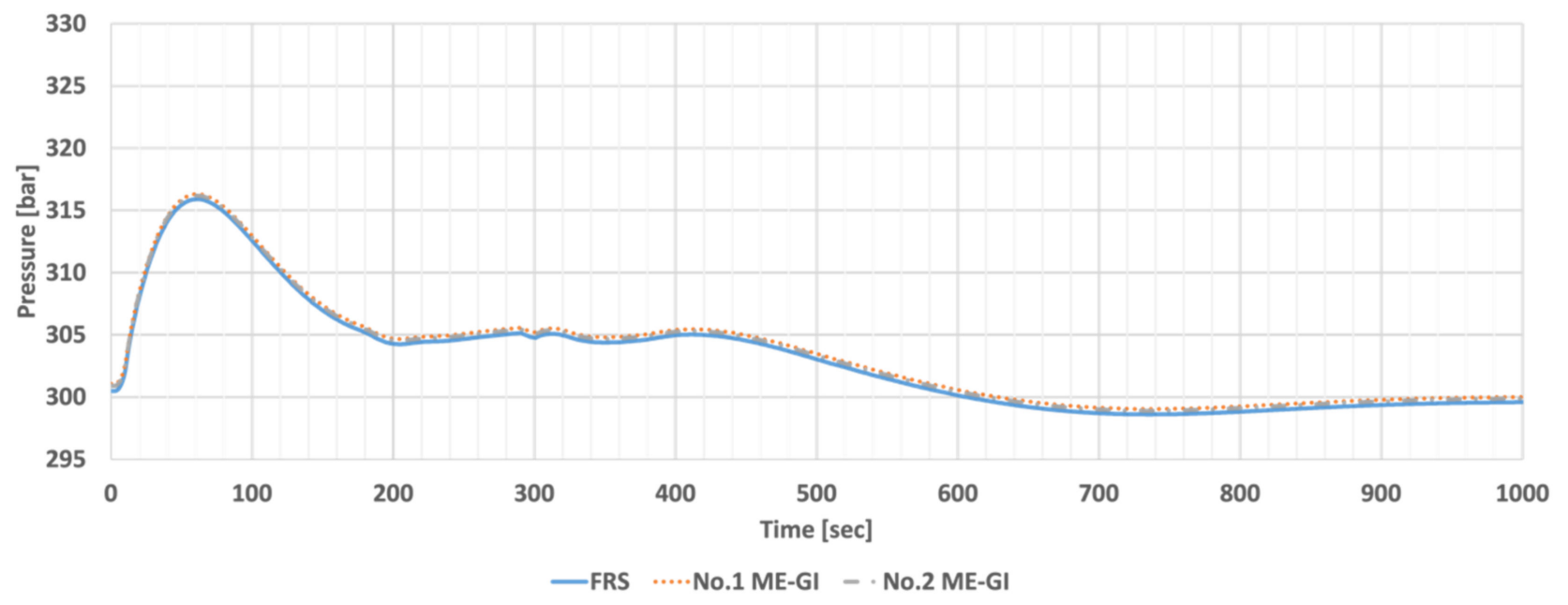

Figure 9. Pressure of each line when one engine is tripped.

When the No.1 ME-GI engine is tripped, the bypass valves installed at the BOG compressors are opened at 300 bar for controlling the downstream pressure of the BOG compressors. In the case of the bypass valve, it is partially opened according to a signal from the multi-controller to adjust the pressure of both suction and discharge, as shown in Figure 3. It starts to close slowly when the pressure reaches the set pressure 300 bar in about $600 \mathrm{~s}$, but partly opens the bypass valve for pressure adjustment at the suction of 
the compressor. The JTV installed in the FRS is also starting to increase its opening ratio to reduce the downstream pressure of the BOG compressors. They are set to operate relatively slower than the OPV in order to prevent large fluctuations in pressure according to the operation of the bypass valves and the JTV. Even in the case of the OPVs, they start to close around $140 \mathrm{~s}$ when the pressure reaches 308 bar. However, when the valves close abruptly, the pressure in the system rises again. So it must start to close slowly. Figure 10 explains how these valves are operated.

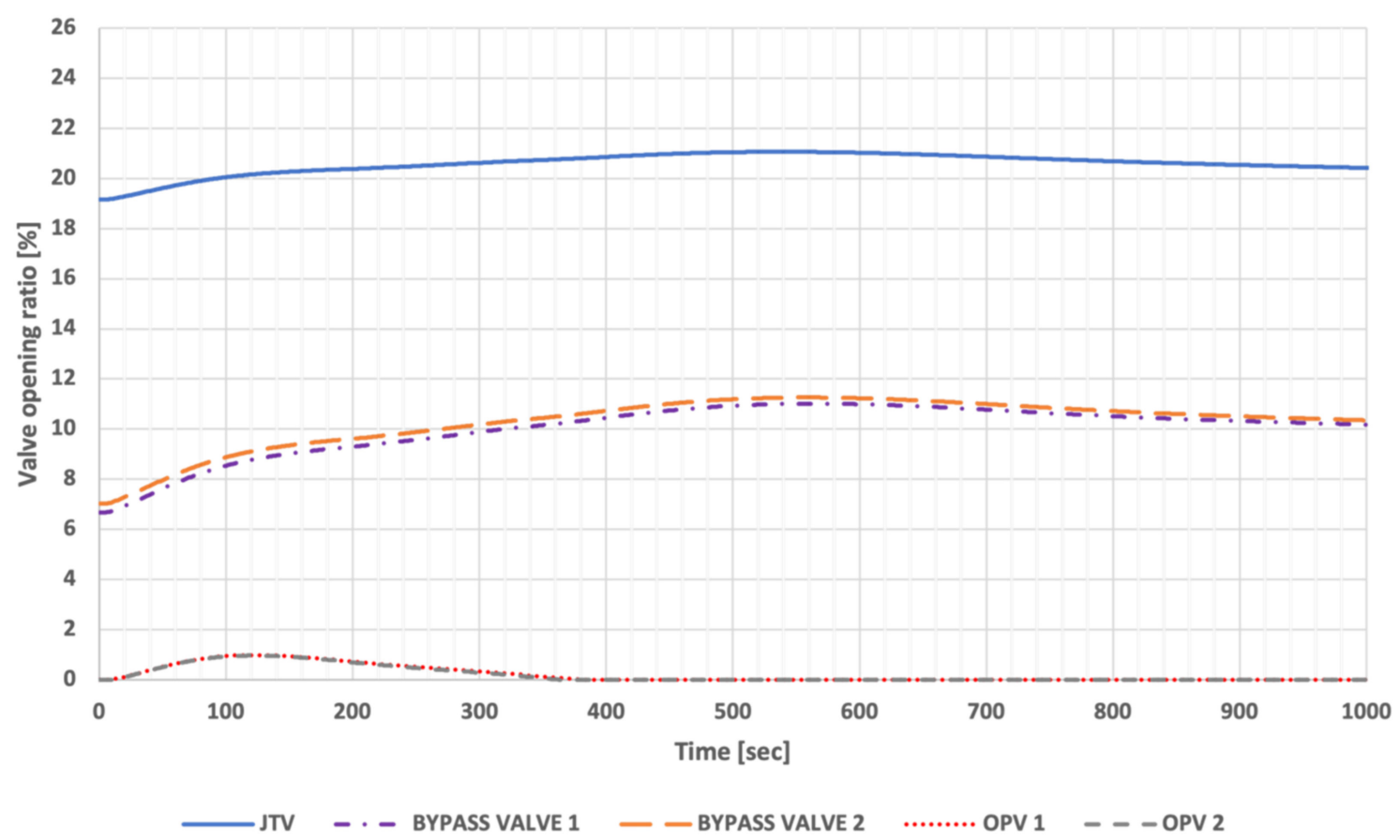

Figure 10. Valve opening ratio when one engine is tripped.

Then two engine trips are reviewed. When two ME-GI engines are tripped, the discharge pressure of each BOG compressor rises to a maximum 328.7 bar. The BOG compressors are tripped because the pressure exceeds 323 bar, which makes it impossible to use the FGSS and the re-liquefaction system. Figure 11 shows each line's pressure.

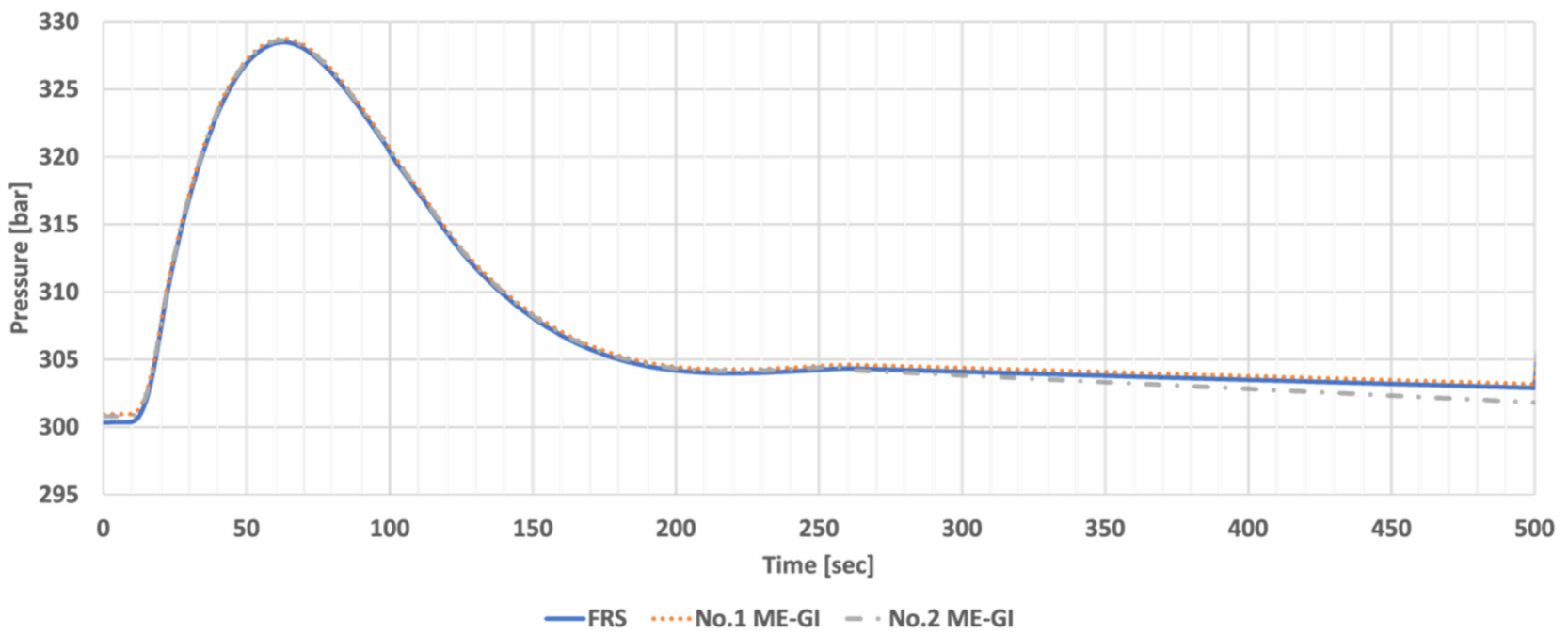

Figure 11. Pressure of each line when two engines are tripped. 
Although the bypass valves, OPVs, and the JTV are operated as shown in Figure 12, this is insufficient to prevent the trip of the BOG compressors. The downstream pressure control may be possible if the pressure controller is tuned quickly, but it is not recommended as it can react excessively to small pressure fluctuations and make the entire system unstable.

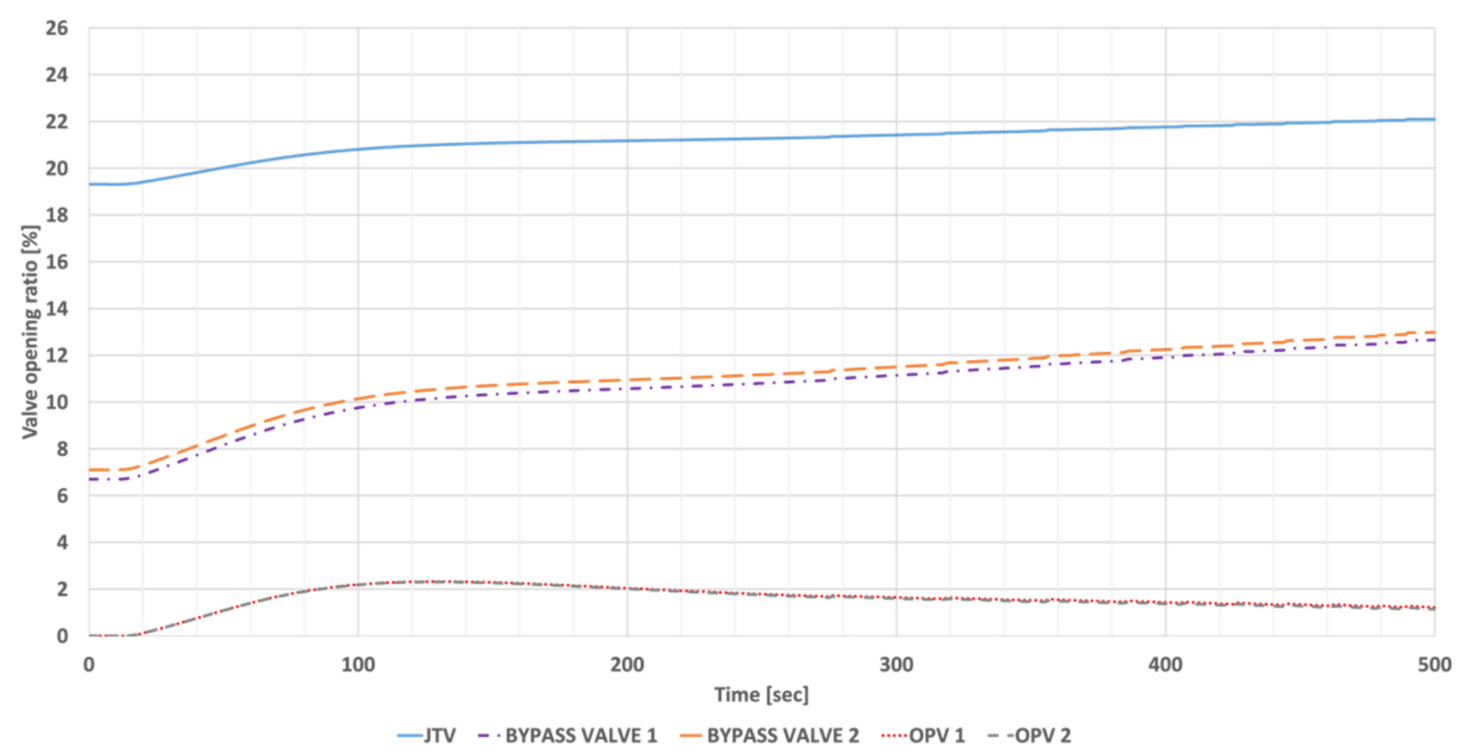

Figure 12. Valve opening ratio when two engines are tripped.

\subsubsection{Case B Results}

When the No.1 ME-GI engine is tripped, the downstream pressure of the No.1 BOG compressor rises to 318.7 bar. However, the piping line of the No.2 ME-GI engine reaches 303.8 bar because it is controlled by the OPV of the FRS, the bypass valve of the No.2 BOG compressor, and the OPV for No.2 ME-GI piping lines. In the case of the FRS, it reaches 157.8 bar. When the pressure in the piping line of the ME-GI engines reaches 308 bar, the No.3 OPV is closed, bringing the pressure to 157.8 bar around $150 \mathrm{~s}$. Figure 13 shows each line's pressure curve when the No.1 ME-GI engine is tripped.

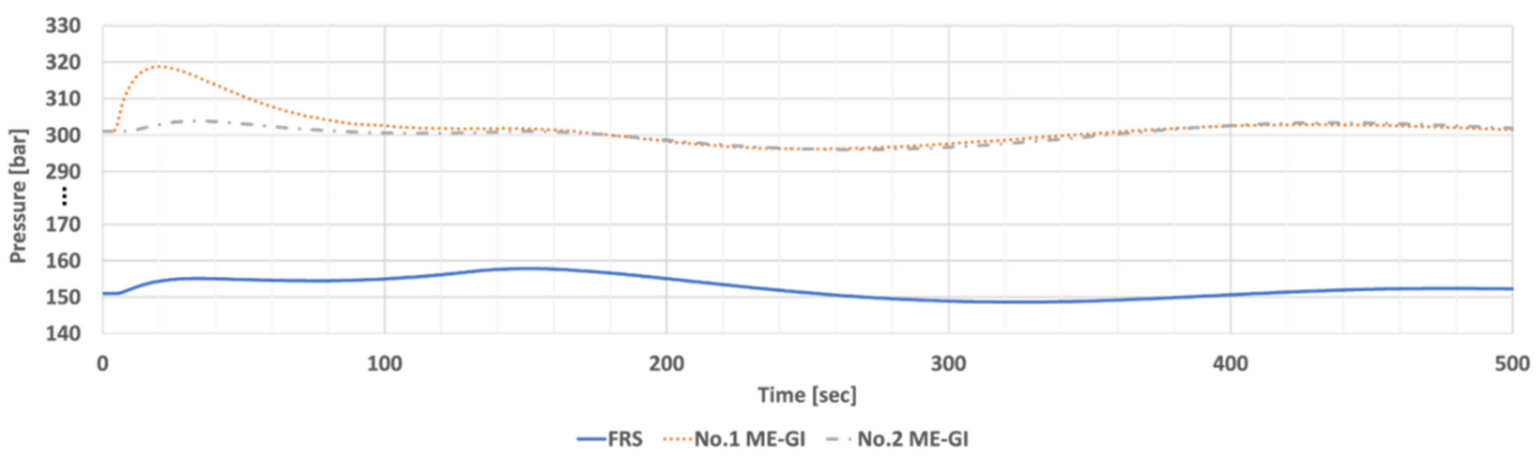

Figure 13. Pressure of each line when one engine is tripped.

Figure 14 explains how these valves, such as the JTV, are operated during the No.1 ME-GI engine trip. The bypass valves installed at the BOG compressors are opened at $150 \mathrm{bar}$ and 300 bar to control the downstream setting pressure of the BOG compressors. If the downstream pressure of the BOG compressors rises to 154 bar and 308 bar, the OPVs are opened. In that case, the No.3 OPV is closed as a result of the pressure of the piping line of the ME-GI engines, and the No.1 bypass and No.2 bypass for 150 bar installed at the BOG compressors are opened more to control the FRS line's pressure. 


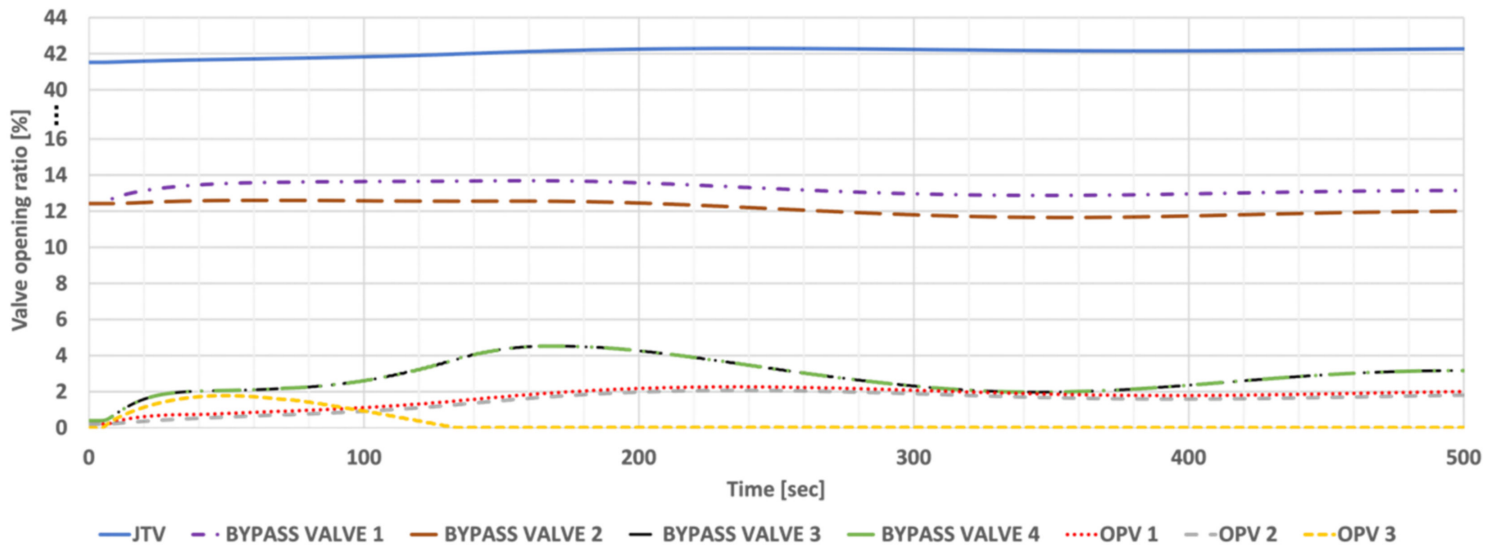

Figure 14. Valve opening ratio when one engine is tripped.

When two ME-GI engines are tripped, the downstream pressure of each BOG compressor rises to 322.5 bar. However, the FRS reaches 163.9 bar. The BOG compressors are tripped because the pressure exceeds the trip value of 163 bar at the FRS line. Figure 15 represents the pressure at each engine line and the FRS line.

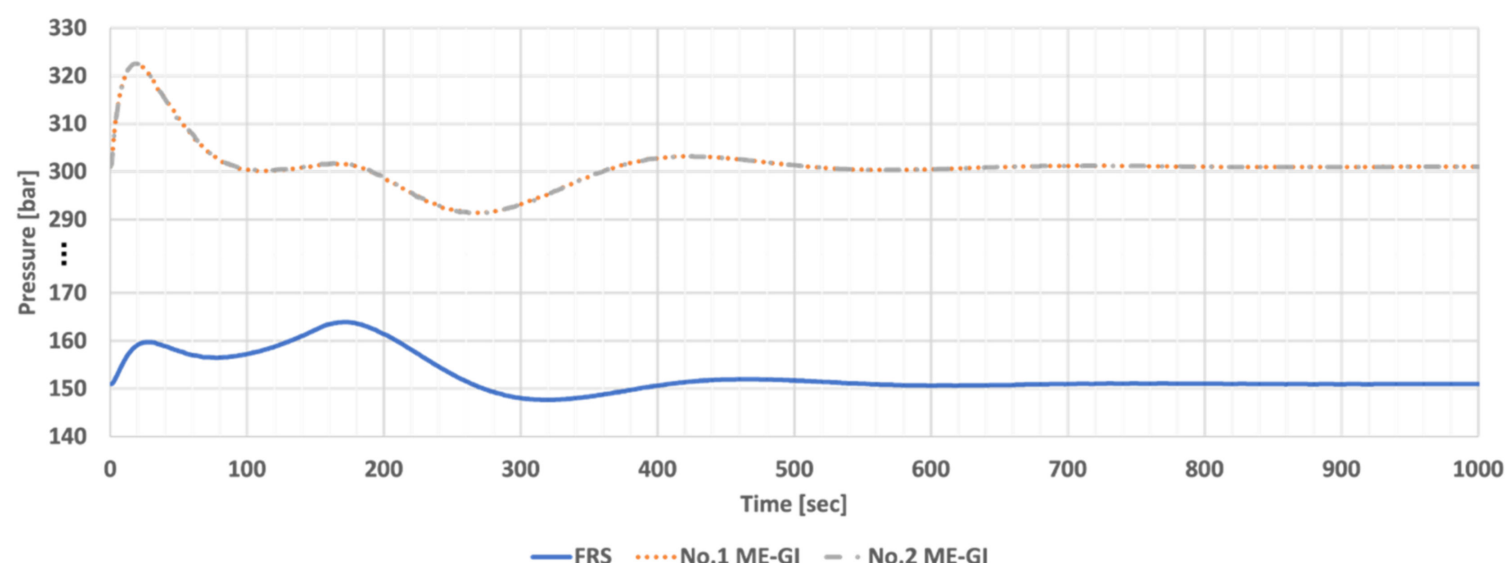

Figure 15. Pressure of each line when two engines are tripped.

Although the bypass valves, OPVs, and the JTV are operated normally, as shown in Figure 16, this is insufficient to prevent the trip of the BOG compressors. When the pressure on the ME-GI engine reaches 308 bar, the No.3 OPV installed in the FRS line is closed and the pressure in the FRS line rises. At approximately $150 \mathrm{~s}$, the pressure reaches 163.9 bar in the fully closed condition of No.3 OPV.

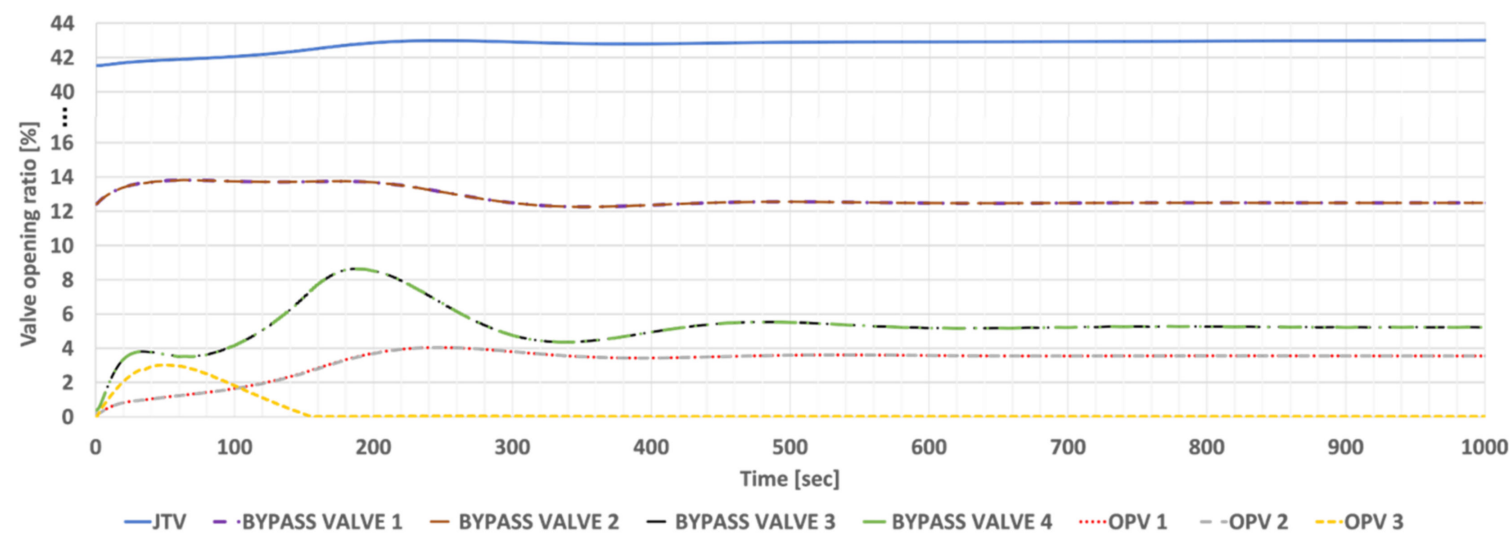

Figure 16. Valve opening ratio when two engines are tripped. 


\subsubsection{Case C Results}

The downstream pressure of the No.1 BOG compressor rises to 320.0 bar when the No.1 ME-GI engine is tripped. In the case of the No.2 ME-GI engine, it reaches 306.6 bar. In addition, the FRS line reaches about 159.6 bar. Figure 17 shows each line's pressure curve when the No.1 ME-GI engine is tripped. Each OPV does not refer to the pressure of other lines and is controlled only by the pressure of these lines, so the pressure appears to be slightly higher than Case B.

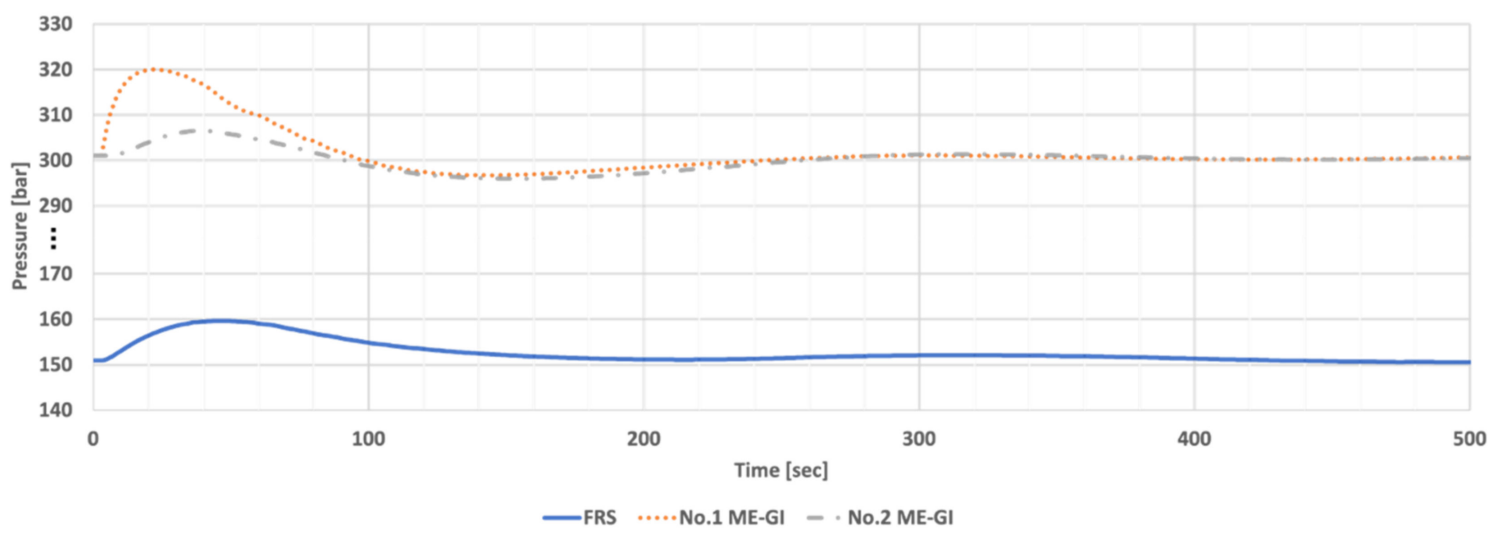

Figure 17. Pressure of each line when one engine is tripped.

Figure 18 explains how these valves work during the No.1 ME-GI engine's trip. In Case C, the multi-controller is not applied, and the OPV installed in each line is controlled by referring to the pressure of the corresponding line, so the valve opening ratio is different from Case B. For the FRS line, each bypass line of the BOG compressor for the FRS is first operated. Then, the No.3 OPV works slightly later than each bypass line of the BOG compressor to control the pressure of the FRS line.

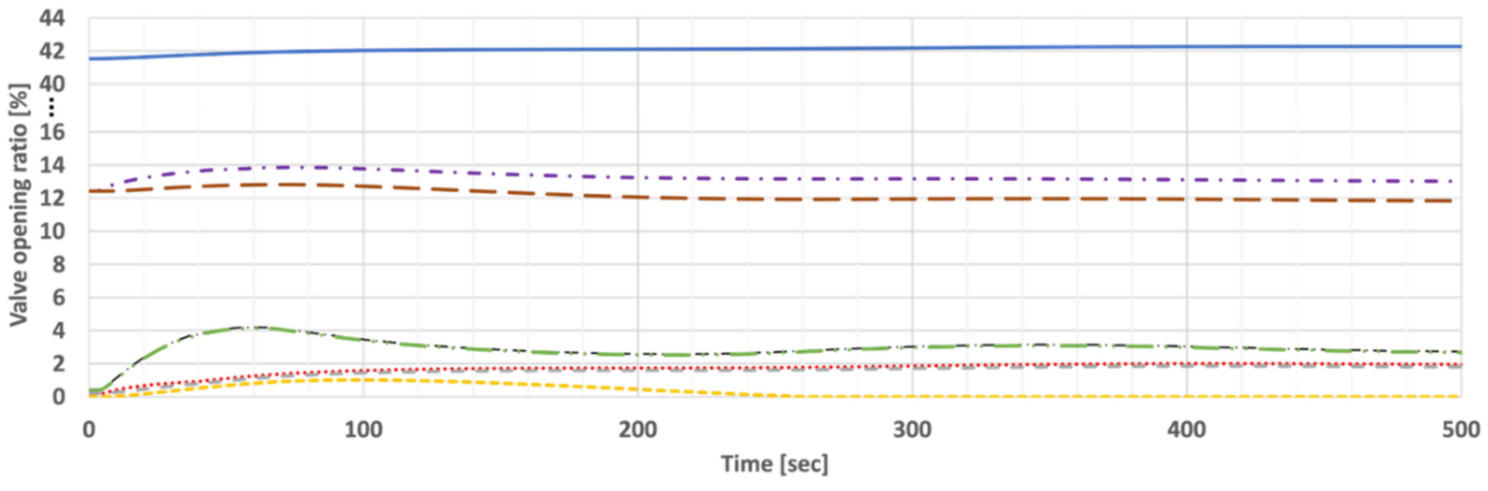

-JTV - BYPASS VALVE 1 - BYPASS VALVE 2 - - BYPASS VALVE 3 - BYPASS VALVE 4 -....OPV 1 - -OPV 2 - - OPV 3

Figure 18. Valve opening ratio when one engine is tripped.

If two ME-GI engines are tripped, the downstream pressure of each BOG compressor rises to 322.3 bar. However, the FRS reaches 168.1 bar. The BOG compressors are tripped from the pressure exceeding 163 bar at the FRS line. Figure 19 represents the pressure at each engine line and the FRS line.

Although the bypass valves, OPVs, and the JTV work according to the signals of the pressure transmitter on each line, as shown in Figure 20, this is not enough to prevent the trip of the BOG compressors. The pressure in the FRS line may not have exceeded the trip setting value if the multi-controller was applied and each signal from the pressure transmitters was used. This means that if the No. 1 OPV and No. 2 OPV are opened more by the multi-controller and the opening signals from the pressure transmitters of each line, this might have prevented the trips of the BOG compressors. 


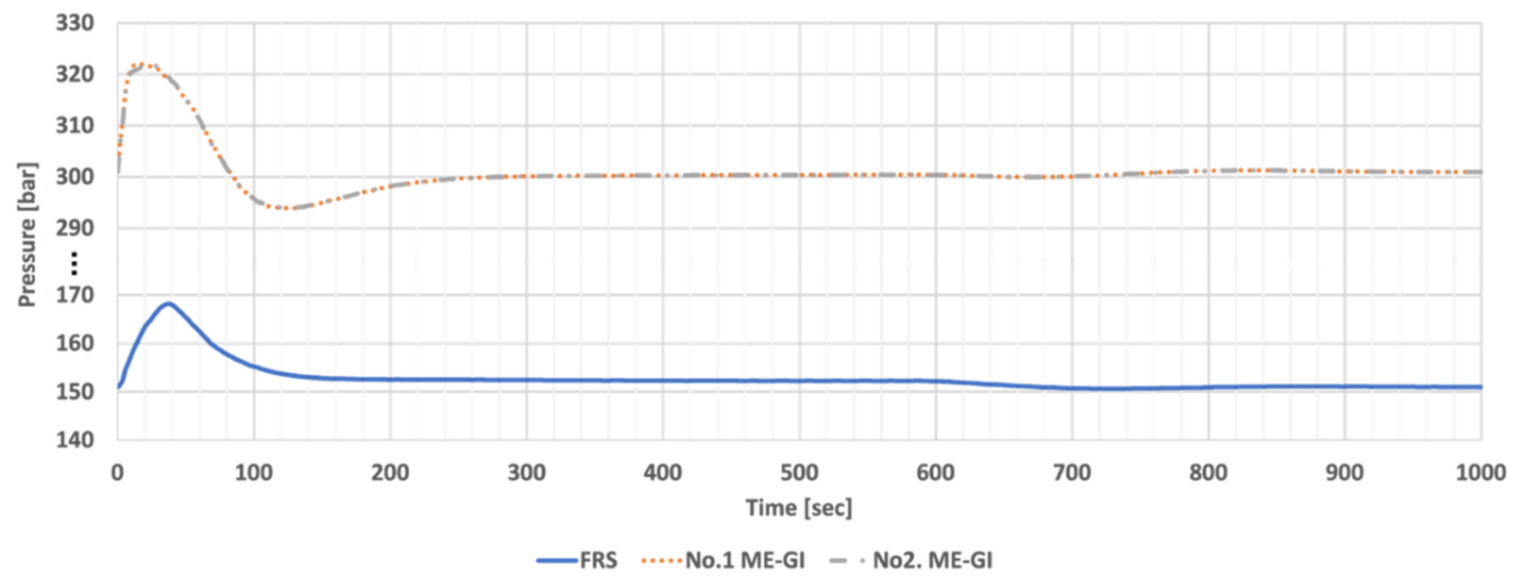

Figure 19. Pressure of each line when two engines are tripped.

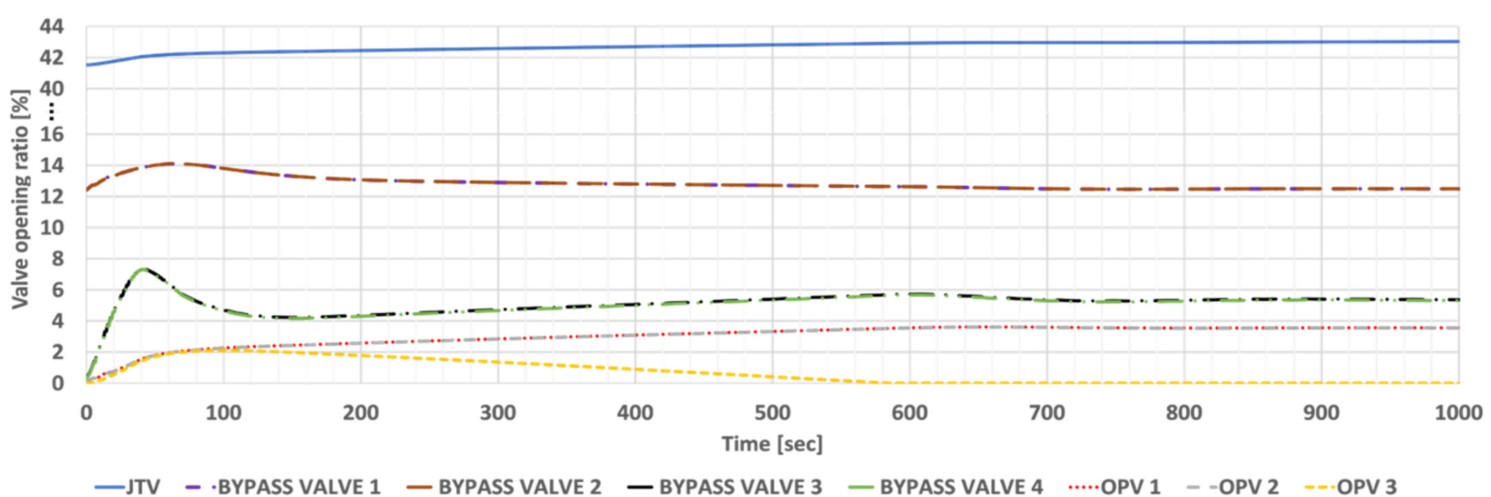

Figure 20. Valve opening ratio when two engines are tripped.

\subsubsection{Case D Results}

When the No.1 ME-GI engine is tripped, lines for the No. 1 ME-GI and No. 2 ME-GI reach 318.7 and 303.8 bar. The FRS line reaches 155.0 bar. Figure 21 shows each line's pressure curve when the No. 1 ME-GI engine is tripped.

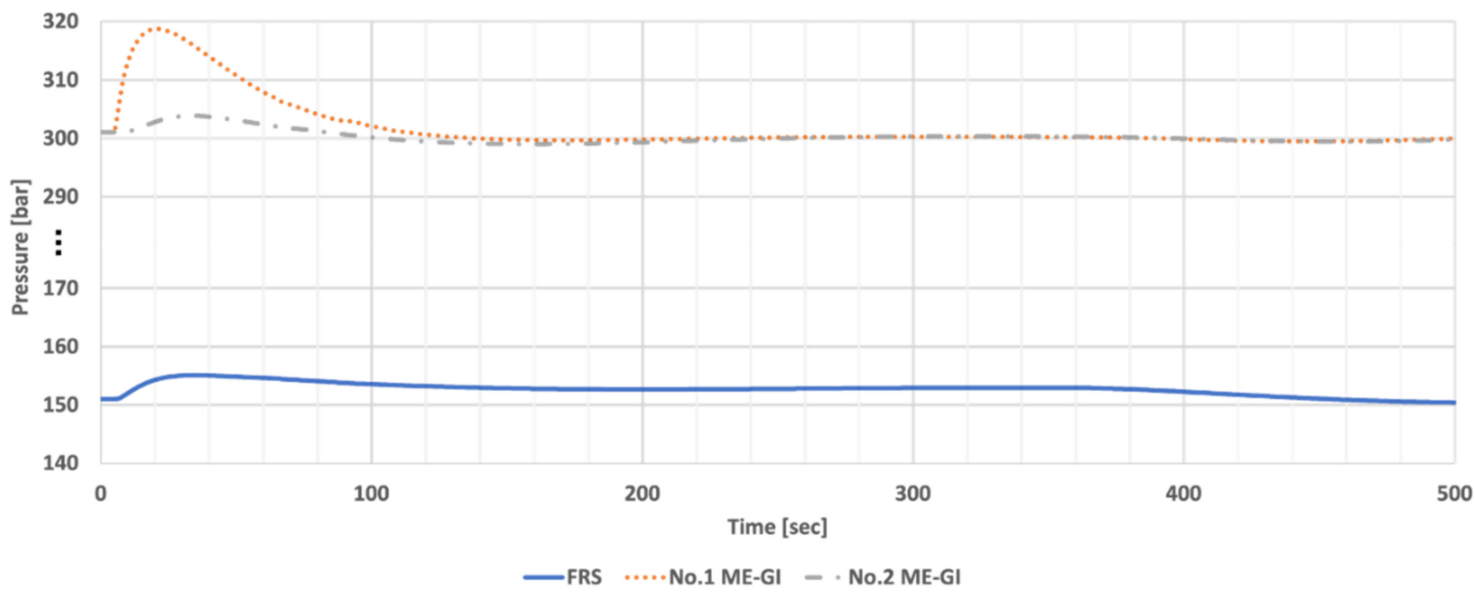

Figure 21. Pressure of each line when one engine is tripped.

Figure 22 shows how these valves work after the trip of the No. 1 ME-GI engine. When the No. 3 OPV reaches a set value of the pressure, it is closed. After the close of No.3 OPV, all bypass valves for the FRS and the ME-GI engines are used to control 150 bar and 300 bar of the downstream pressure of each BOG compressor. 


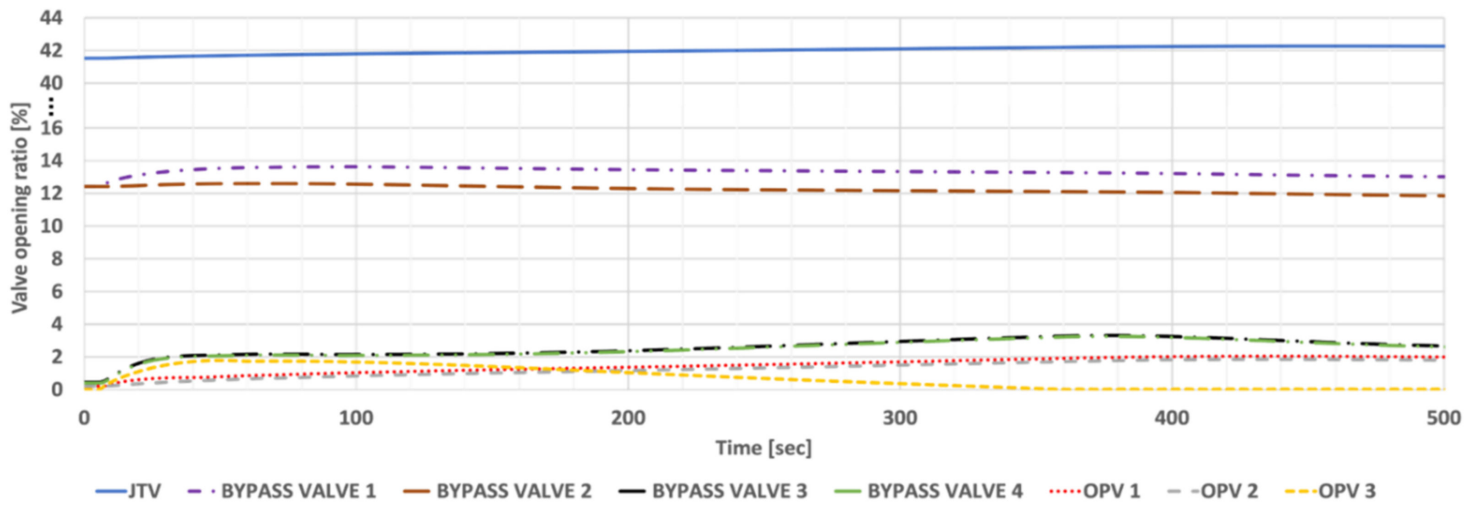

Figure 22. Valve opening ratio when one engine is tripped.

If two ME-GI engines are tripped, the downstream pressure of each BOG compressor rises to 322.2 bar. In addition, the FRS reaches about 159.7 bar. By effectively controlling the OPVs using the multi-controller, even if two engines are tripped, the BOG compressors are not tripped. Figure 23 explains the pressure at each engine line and the FRS line.

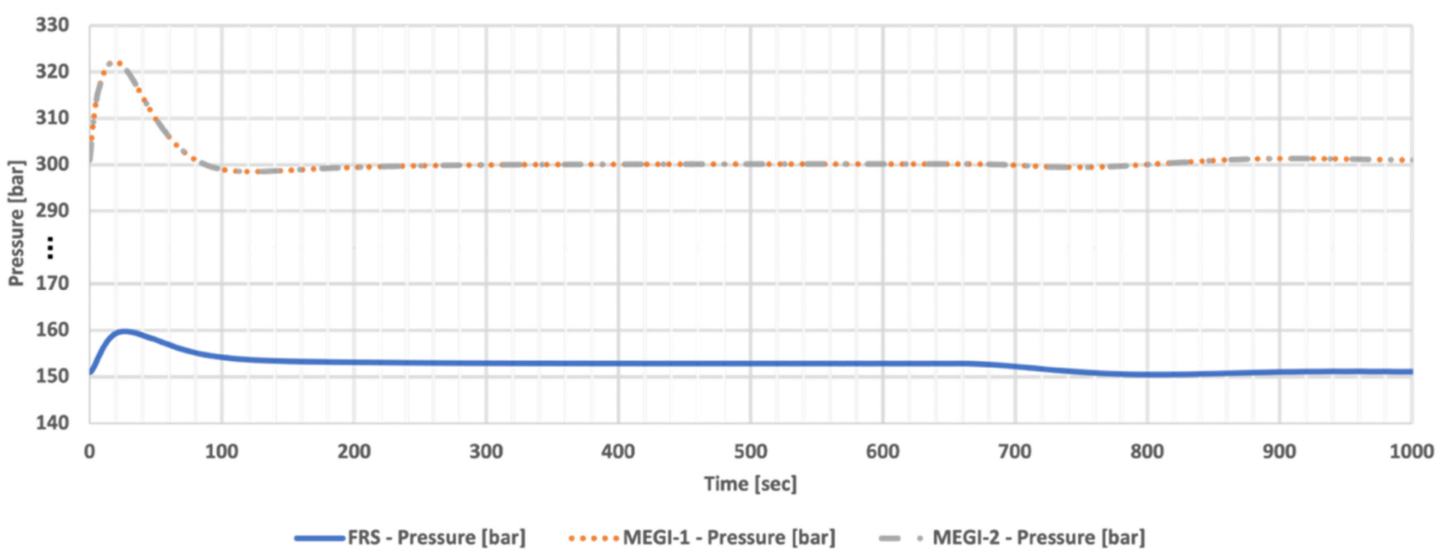

Figure 23. Pressure of each line when two engines are tripped.

When two ME-GI engines are tripped, the No.3 OPV and bypass valves for the 150 bar line of the BOG compressors are opened quickly to handle the large flowrates of the BOG and prevent pressure build-up. During this time, the No. 1 bypass valve, No. 2 bypass valve, and the No.1 and 2 OPVs are operated relatively slower than the No.3 OPV so it does not exceed the trip value. Figure 24 represents how these valves work after the trips of the two engines.

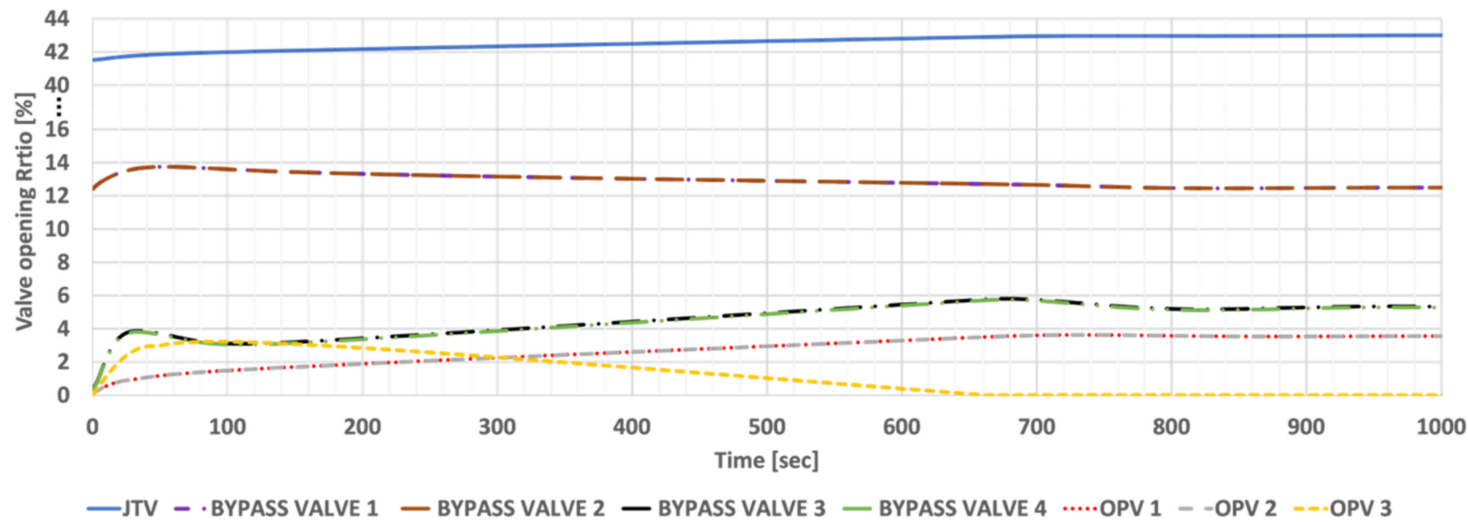

Figure 24. Valve opening ratio when two engines are tripped. 


\subsection{Performance Analysis of Processible BOG Amount}

The BOG management capability according to ship's speed is examined. As the pressure of the re-liquefaction system changes from 300 to 150 bar, it is necessary to check the amount of BOG that could be handled according to the sailing speed of the ship. If the amount of gas that could be processed by the ME-GI engines, DFGEs, and re-liquefaction system is greater than the amount of BOG generated in the cargo tanks, it is considered to have sufficient performance for BOG management in the FGSS and the re-liquefaction system. In most cases, the two sets of ME-GI engines and the three sets of DFGEs are operated while the FRS is operated. The processable gas quantity is expressed as Equation (10) referring to Figure 25 showing mainly the flowrate of the system.

Processable gas quantity $=$ Reliquefaction $(A 3)+$ MEGI engines (A4) + DFGEs (A5)

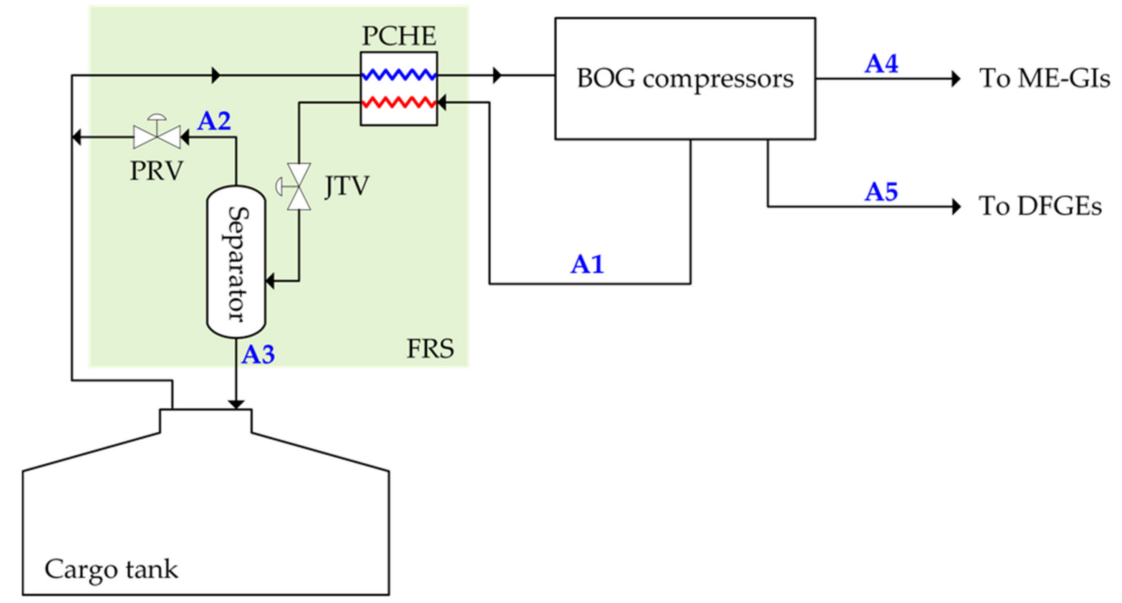

Figure 25. Schematic diagram of the main flowrate.

The amount of BOG generated in the cargo tanks is $3713 \mathrm{~kg} / \mathrm{h}$ when calculated considering the boil-off rate, the filling ratio, the cargo tank size, and the LNG compositions described in the Section 3 of this paper. The speed of the vessel is chosen as the speed commonly used for LNGC navigations. In the case of anchorage, the FRS is used before entering port in order to reduce pressure inside the cargo tanks, so this case is excluded. Table 5 describes how much BOG can be processed in the typical system (Case A) and the newly proposed system (Cases B to D).

Table 5. Manageable BOG amounts.

\begin{tabular}{|c|c|c|c|c|c|c|}
\hline $\begin{array}{c}\text { System } \\
\text { (unit) }\end{array}$ & Action Item & 15 Knots & 16 Knots & 17 Knots & 18 Knots & 19 Knots \\
\hline \multirow{6}{*}{$\begin{array}{c}\text { Case A } \\
(\mathrm{kg} / \mathrm{h})\end{array}$} & FRS (A1) & 2941 & 3071 & 3180 & 3266 & 4127 \\
\hline & Vapor (A2) & 1136 & 1188 & 1223 & 1230 & 1936 \\
\hline & Re-liquefaction (A3) & 1810 & 1883 & 1957 & 2036 & 2191 \\
\hline & ME-GIs (A4) & 1250 & 1500 & 1800 & 2200 & 2500 \\
\hline & DFGEs (A5) & 900 & 900 & 900 & 900 & 900 \\
\hline & Processed BOG & 3960 & 4283 & 4657 & 5136 & 5591 \\
\hline \multirow{6}{*}{$\begin{array}{l}\text { Case B to D } \\
\qquad(\mathrm{kg} / \mathrm{h})\end{array}$} & FRS (A1) & 6111 & 6037 & 5972 & 5896 & 5826 \\
\hline & Vapor (A2) & 4459 & 4364 & 4276 & 4170 & 4073 \\
\hline & Re-liquefaction (A3) & 1652 & 1673 & 1696 & 1726 & 1753 \\
\hline & ME-GIs (A4) & 1250 & 1500 & 1800 & 2200 & 2500 \\
\hline & DFGEs (A5) & 900 & 900 & 900 & 900 & 900 \\
\hline & Processed BOG & 3802 & 4073 & 4396 & 4826 & 5153 \\
\hline
\end{tabular}


The amount of processable BOG in the newly proposed system (Cases B to D), compared to Case A, has a small flowrate of approximately 150 to $400 \mathrm{~kg} / \mathrm{h}$. However, considering the amount of the BOG generated in the cargo tanks, it is confirmed by the proposed system that it could operate reliably by controlling the pressure inside the cargo tanks without operation of the gas combustion units. In addition, there is no degradation in the amount of the re-liquefaction by the lubricant oils.

\section{Discussion}

As the objective of this study, we proposed a novel control strategy in a new configuration for the stable operation of a re-liquefaction system and a fuel gas supply system during abnormal operations such as trips of major equipment. To analyze the performance of the proposed systems, dynamic simulation was used in UniSim R.460.2. In the simulation, it was limited to the fuel gas supply system and the re-liquefaction system of the LNG carriers. For gas consumers such as ME-GI engines, only the quantity of gas consumption was used. The controllers were tuned in consideration of the fact that, if controlled quickly, it reacts excessively to small pressure fluctuations, making the entire system unstable. According to the simulation results, the newly proposed system is reliably able to operate by focusing on the pressure controllability and the processible BOG quantity when the main propulsion engines (ME-GI engines), which consume the highest amount of fuel gas in the LNG carriers, are tripped. In addition, the amount of BOG consumed by the engines and liquefied in the re-liquefaction system can completely handle the BOG generated in the cargo tanks. There was a difference of about 150 to $400 \mathrm{~kg} / \mathrm{h}$ compared to the amount of BOG that could be processed in the typical fuel gas system and re-liquefaction system. However, it can be concluded that there is no significant difference in that the BOG generated in the cargo tanks can be handled in the newly proposed system. Furthermore, there is no degradation in the amount of re-liquefaction by the lubricant oils compared to the typical fuel gas supply system and the re-liquefaction system.

(1) When applying the novel configuration that we proposed, it is advantageous to have a certain amount of the re-liquefaction, low operating expenses (OPEX), and stable operation regardless of the fuel gas consumer's trips. In terms of the stable reliquefaction, the proposed configuration prevents delivery of the oil, which is used for lubricating inside the cylinders of the BOG compressors, to the PCHE because 150 bar can be compressed without any lubricants, unlike 300 bar. This means the lubricant oil can be prevented from freezing inside the PCHE under cryogenic conditions and degrading its re-liquefaction performance. When clogging occurs in the PCHE from the lubricant oil, the quantity of re-liquefaction is decreased by the thermal hydraulic imbalance inside the PCHE and the reduction in the heat exchange area. It is technically difficult to apply oil-free in the cylinders of a BOG compressor that supplies 300 bar. Moreover, since there is no clogging of lubricating oil inside the PCHE, there is no need to clean the PCHE, which is difficult to maintain on board, and this is quite beneficial from the viewpoint of OPEX. Considering the stable operation, the BOG compressors should not be abruptly stopped by the trip, unlike the operator's intention even if the ME-GI engines with the most fuel gas usage are tripped. When the BOG compressors are tripped, preventing BOG management, the BOG must be consumed in the GCU through the free-flow to prevent a pressure increase in the cargo tanks. However, in the novel configuration, control methods become an important issue with the addition of 150 bar piping lines to the re-liquefaction system. In this proposal, three control strategies are presented and reviewed to enable the stable operation of the BOG compressors focusing on trips of the ME-GI engines with the most fuel gas usage. The reviews are carried out by UniSim dynamic simulation. Table 6 shows the summary of the review results. The recommendable control method is Case D, because the multi-controller compares the set values by referring to the pressure in the line where the pressure transmitter is installed, and controls them 
more efficiently, even if the two main propulsion engines are tripped. This means that the BOG compressors are operated well without any trips.

(2) When focusing on the BOG management, the typical configuration (Case A) shows a better performance regarding the amount of re-liquefaction than the proposal (Case D), shown in Table 4. Although a manageable BOG of approximately 150 to $400 \mathrm{~kg} / \mathrm{h}$ in Case D is reduced by the fuel gas supply system and the re-liquefaction system compared to Case A, Case D is a better choice considering the stability during the trips of the BOG compressors, the reduction in the amount of re-liquefaction caused by the oil clogging, and the required maintenance work on the PCHE from the oil clogging.

Table 6. Summary of dynamic simulation results.

\begin{tabular}{lcccccc}
\hline \multirow{2}{*}{ System (Unit) } & \multicolumn{3}{c}{ One Engine Trip } & \multicolumn{3}{c}{ Two Engine Trips } \\
\cline { 2 - 7 } & No.1 ME-GI & No.2 ME-GI & FRS & No.1 ME-GI & No.2 ME-GI & FRS \\
\hline Case A (bar) & 316.2 & 316.1 & 315.8 & 328.7 & 328.6 & 328.4 \\
Case B (bar) & 318.7 & 303.8 & 157.8 & 322.5 & 322.5 & 163.9 \\
Case C (bar) & 320.0 & 306.6 & 159.6 & 322.3 & 322.3 & 168.1 \\
Case D (bar) & 318.7 & 303.8 & 155.0 & 322.2 & 322.2 & 159.7 \\
\hline
\end{tabular}

In future work, we will examine not only the contents of this study but also more efficient cases, and will compare performance through simulation and actual testing.

\section{Patents}

The patent for the mechanical configuration was registered at the Korean Intellectual Property Office on 4 March 2020. Patent applicant is Daewoo Shipbuilding and Marine Engineering, and the patent developer is Soon-kyu Hwang. (Patent register number: 1020871800000)

Author Contributions: Conceptualization, S.-K.H.; methodology, S.-K.H.; software, S.-K.H.; writingoriginal draft preparation, S.-K.H.; writing-review and editing, S.-K.H. and B.-G.J.; supervision, S.-K.H. and B.-G.J. All authors have read and agreed to the published version of the manuscript.

Funding: This research received no external funding.

Institutional Review Board Statement: Not applicable.

Informed Consent Statement: Not applicable.

Data Availability Statement: Not applicable.

Acknowledgments: Appreciation to HEATRIC for sharing an original figure of the PCHE and for allowing the use of a PCHE figure in this paper. In addition, thank the MDPI staff and the reviewers for making this paper better.

Conflicts of Interest: The authors declare no conflict of interest.

\section{References}

1. Thomson, H.; Corbett, J.J.; Winebrake, J.J. Natural gas as a marine fuel. Energy Policy 2015, 87, 153-167. [CrossRef]

2. Kim, A.; Seo, Y. The reduction of Sox emission in the shipping industry: The case of Korean companies. Mar. Policy 2015, 100, 98-106. [CrossRef]

3. Lindstad, E.; Bø, T.I. Potential power setups, fuels and hull designs capable of satisfying future EEDI requirements. Transp. Res. Part D 2018, 63, 276-290. [CrossRef]

4. Air Pollution. Available online: https://www.imo.org/en/OurWork/Environment/PollutionPrevention/AirPollution/Pages/ Default.aspx (accessed on 1 June 2021).

5. Energy Efficiency Measures. Available online: http://www.imo.org/en/OurWork/Environment/PollutionPrevention/ AirPollution/Pages/Technical-and-Operational-Measures.aspx (accessed on 1 June 2021).

6. Zakaria, N.M.G.; Corbett, J.J.; Rahman, S. Energy efficiency design index (EEDI) for inland vessels in Bangladesh. Procedia Eng. 2017, 194, 362-369. [CrossRef] 
7. Ekanem Attah, E.; Bucknall, R. An Analysis of the Energy Efficiency of LNG Ships Powering Options Using the EEDI. Ocean Eng. 2015, 110, 62-74. [CrossRef]

8. Marine Diesel Engines How Efficient Can a Two-Stroke Engine. Available online: https://www.stg-online.org/onTEAM/ shipefficiency/programm/Clausen.pdf (accessed on 9 October 2021).

9. Plessas, T.; Kanellopoulou, A.; Zaraphonitis, G.; Papanikolaou, A.; Shigunov, V. Exploration of Design Space and Optimisation of RoPax Vessels and Containerships in View of EEDI and Safe Operation in Adverse Sea Conditions. Ocean Eng. 2018, 162, 1-20. [CrossRef]

10. Nikolaos, K.; Christos, P.; Dimitrios, F. A comparative techno-economic analysis of TFDE, ME-GI and X-DF propulsion systems for LNG carriers. In Proceedings of the Case Study for Alternative Multi-Annual Operational Profiles, IAME 2019 Conference, Athens, Greece, 25-28 June 2019.

11. Dwivedi, S.N. Design considerations for high-pressure reciprocating compressors for refinery services. In Proceedings of the International Compressor Engineering Conference, West Lafayette, IN, USA, 17-20 July 1990.

12. Tsuzuki, N.; Kato, Y.; Ishiduka, T. High Performance Printed Circuit Heat Exchanger. Appl. Therm. Eng. 2007, $27,1702-1707$. [CrossRef]

13. Heatric-PCHE. Available online: https://www.heatric.com/ (accessed on 9 October 2021).

14. Fernández, I.A.; Gómez, M.R.; Gómez, J.R.; Insua, Á.B. Review of Propulsion Systems on LNG Carriers. Renew. Sustain. Energy Rev. 2017, 67, 1395-1411. [CrossRef]

15. Park, H.; Lee, S.; Jeong, J.; Chang, D. Design of the Compressor-Assisted LNG Fuel Gas Supply System. Energy 2018, 158, 1017-1027. [CrossRef]

16. Tan, H.; Shan, S.; Nie, Y.; Zhao, Q. A New Boil-off Gas Re-Liquefaction System for LNG Carriers Based on Dual Mixed Refrigerant Cycle. Cryogenics 2018, 92, 84-92. [CrossRef]

17. Kim, D.; Hwang, C.; Gundersen, T.; Lim, Y. Process Design and Economic Optimization of Boil-off-Gas Re-Liquefaction Systems for LNG Carriers. Energy 2019, 173, 1119-1129. [CrossRef]

18. Wei, W.; Ding, G.; Hu, H.; Wang, K. Influence of Lubricant Oil on Heat Transfer Performance of Refrigerant Flow Boiling inside Small Diameter Tubes. Part I: Experimental Study. Exp. Therm. Fluid Sci. 2007, 32, 67-76. [CrossRef]

19. Tran, N.; Sheng, S.-R.; Wang, C.-C. An Experimental Study and Empirical Correlations to Describe the Effect of Lubricant Oil on the Nucleate Boiling Heat Transfer Performance for R-1234ze and R-134a. Int. Commun. Heat Mass Transf. 2018, 97, 78-84. [CrossRef]

20. Won, W.; Lee, K.S. Delta-Operator-Based Adaptive Model Predictive Control and Online Optimization of a Natural Gas Liquefaction Process. Chem. Eng. Sci. 2017, 162, 21-32. [CrossRef]

21. Sun, H.; Shu, D.; Jiang, Z. Simulation Study of the Dynamic Performance of a MRC Plant with Refrigerant Charged or Leaked. Cryogenics 2012, 52, 8-12. [CrossRef]

22. Kim, H.J.; Park, C.C.; Lee, J.Y.; Lee, C.S.; Kim, M.H. Operational Characteristics of Propane-Mixed Refrigerant Liquefaction Process for Application to $30 \mathrm{Kg} / \mathrm{h}-$ Scale LNG Plant: Mixed Refrigerant Supply and Its Effect on Natural Gas Temperature. J. Mech. Sci. Technol. 2016, 30, 1883-1890. [CrossRef]

23. Yang, S.; Fu, B.; Hou, Y.; Chen, S.; Li, Z.; Wang, S. Transient Cooling and Operational Performance of the Cryogenic Part in Reverse Brayton Air Refrigerator. Energy 2019, 167, 921-938. [CrossRef]

24. System and Method for Processing Boil-off Gas for a Marine Structure. Available online: https://patents.google.com/patent/ KR20130139150A/en (accessed on 1 June 2021).

25. Hanlon, P.C. (Ed.) Compressor Handbook, 1st ed.; Chapter 21; McGraw-Hill Education: New York, NY, USA, 2001; Volume 3, pp. 680-683.

26. Wang, L.; Liu, G.B.; Zhao, Y.Y.; Li, L.L. Performance Comparison of Capacity Control Methods for Reciprocating Compressors. IOP Conf. Ser. Mater. Sci. Eng. 2015, 90, 12029. [CrossRef]

27. Capacity Control of Reciprocating Compressors. Available online: https://www.controlglobal.com/articles/2016/capacitycontrol-of-reciprocating-compressors / (accessed on 9 October 2021).

28. Liquefied Natural Gas for Europe-Some Important Issues for Consideration-Google Scholar. Available online: https: / / scholar.google.com/scholar_lookup?title=Liquefied\%20natural\%20gas\%20for\%20europe\%20-\%20some \%20important\%20 issues $\% 2$ for $\% 20$ consideration. $\% 20$ EUR $\% 20 \%$ E2\%80\%93\%20scientific $\% 20$ and $\% 20$ technical $\% 20$ research $\% 20$ series\&author=B. \%20Kavalov\&publication_year=2009 (accessed on 9 October 2021).

29. Miana, M.; Legorburo, R.; Díez, D.; Hwang, Y. Calculation of Boil-Off Rate of Liquefied Natural Gas in Mark III Tanks of Ship Carriers by Numerical Analysis. Appl. Therm. Eng. 2016, 93, 279-296. [CrossRef]

30. Jeong, H.; Shim, W. Calculation of Boil-Off Gas (BOG) Generation of KC-1 Membrane LNG Tank with High Density Rigid Polyurethane Foam by Numerical Analysis. Pol. Marit. Res. 2017, 24, 100-114. [CrossRef]

31. Resolution MSC.391(95). Available online: https://www.register-iri.com/wp-content/uploads/MSC_Resolution_39195.pdf (accessed on 9 October 2021).

32. NO96 System. Available online: https://gtt.fr/technologies/no96-systems (accessed on 9 October 2021).

33. Operation Guide (UniSim®Design); R460 Release; Honeywell International Sàrl: Rolle, Switzerland, 2017; pp. 6-76-6-83.

34. Son, H.; Kim, J. Operability Study on Small-Scale BOG (Boil-off Gas) Re-Liquefaction Processes. Energy 2019, $185,1263-1281$. [CrossRef] 
35. Lee, C.; Song, K.; Lee, Y.; Han, C. A Decomposition Methodology for Dynamic Modeling of Cold Box in Offshore Natural Gas Liquefaction Process. Comput. Chem. Eng. 2016, 84, 546-557. [CrossRef]

36. Emerson Fisher. Control Valve Handbook, 5th ed.; Emerson Fisher: Marshalltown, IA, USA, 2019; pp. 87-110.

37. Bequette, B.W. Process Control: Modeling, Analysis, and Simulation, 1st ed.; Prentice Hall PTR: Upper Saddle River, NJ, USA, 2003; pp. 195-210.

38. Honeywell. Dynamic Modeling using UniSim®Design, R411 ed.; Honeywell: London, ON, Canada, 2016; pp. 4.1-4.21.

39. Durković, R.; Grujičić, R. An Approach to Determine the Minimum Specific Fuel Consumption and Engine Economical Operation Curve Model. Measurement 2019, 132, 303-308. [CrossRef]

40. Two Stroke-Project Guides. Available online: https://marine.man-es.com/two-stroke/project-guides (accessed on 9 October 2021).

41. Wärtsilä 34DF Product Guide. Available online: https://www.wartsila.com/docs/default-source/product-files/engines/ df-engine / product-guide-o-e-w34df.pdf?utm_source=engines\&utm_medium=dfengines\&utm_term=w34df\&utm_content= productguide\&utm_campaign=msleadscoring (accessed on 9 October 2021). 